\title{
OBSERVATIONS ON THE ELECTRA DOLPHIN, PEPONOCEPHALA ELECTRA
}

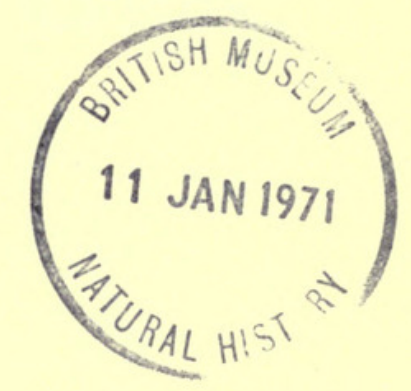

BY

WILLIAM HENRY DAWBIN

BRUCE ALEXANDER NOBLE Kref.

FRANCIS CHARLES FRASER

$P p$. I73-201 ; I3 Text-figures

BULLETIN OF

THE BRITISH MUSEUM (NATURAL HISTORY) ZOOLOGY

Vol. 20 No. 6

LONDON : 1970 
The Bulletin OF The BRitish MUSEum (NATURAL HISTORY), instituted in I949, is issued in five series corresponding to the Departments of the Museum, and an Historical series.

Parts will appear at irregular intervals as they become ready. Volumes will contain about three to four hundred pages, and will not necessarily be completed within one calendar year.

In I965 a separate supplementary series of longer papers was instituted, numbered serially for each Department.

This paper is Vol. 20, No. 6 of the Zoological series. The abbreviated titles of periodicals cited follow those of the World List of Scientific Periodicals.

(C) Trustees of the British Museum (Natural History), I970

World List abbreviation

Bull. Br. Mus. nat. Hist. (Zool.). 


\title{
OBSERVATIONS ON THE ELECTRA DOLPHIN, PEPONOCEPHALA ELECTRA
}

\author{
By W. H. DAWBIN, B. A. NOBLE \& F. C. FRASER
}

\section{INTRODUCTION}

THE notes set down in this paper were stimulated by a stranding of electra dolphins at Crowdy Heads, about 200 miles north of Sydney in August I958. This stranding was reported briefly as a school of blackfish by a local newspaper some days after the event. Following notice of the report one of the authors (W.H.D.) made local enquiry and was told that all the animals had been removed by fishermen and had been cut up for bait. The local postmistress, Mrs. W. J. Ward, had made a careful count of the teeth of one specimen before its removal and stated that there were 22 on each side of the upper jaw and I9 on each side of the lower jaw. This eliminated the possibility that the school might have been pilot whales (Globicephala sp.) the species usually referred to locally as blackfish. The observed tooth row number also ruled out Feresa from consideration.

An immediate search in the Crowdy Heads area failed to unearth any skeletal remains, so with the co-operation of the Australian Broadcasting Commission, both radio and television, appeals were made for any photographs or material which may have been taken by visitors to the beach on the day of the stranding. The response in colour and black and white photographs and in descriptions was good, and a number of the photographs showed quite clearly that most of the animals had a rounded snout without beak, white lips and light thoracic and abdominal patches on an otherwise uniformly dark-coloured background.

During a further visit to the Crowdy Heads area I962 (by W.H.D.) reports inland from the area where received that in the course of removal of the dolphin carcases one had fallen off a truck and had been left behind at the roadside. The skull had been removed by a local resident, $\mathrm{Mr}$. $\mathrm{H}$. Anderson, who generously presented it to the visiting author.

Subsequently a half skull which had been used as bait in a fish trap was secured. This specimen was from a dolphin that had stranded in the Port Macquarie area in January I962. The unprompted description of the dolphin by the fisherman concerned matched those at Crowdy Heads. He had seen the latter animals and was convinced that his specimen was identical with them.

The number of alveoli in the skull of the decomposed carcase and in the half skull essentially confirmed Mrs. Ward's tooth count and from this and from other skull characters the school was provisionally identified as Lagenorhynchus (= Peponocephala) electra (by W.H.D.). The two specimens were sent to the British Museum (Natural History) for comparison with other examples of this species including the holotype. 


\section{OBSERVATIONS ON THE CROWDY HEADS AND PORT MACQUARIE STRANDINGS (W.H.D.)}

Letters referring to the animals prior to stranding were unanimous in describing them as a large school of black dolphins sighted off Port Macquarie heading south between 2 and 4 p.m. on the day preceding the stranding. Crowdy Heads is approximately 40 miles south of Port Macquarie and the animals reached there and commenced stranding during a high tide about ro a.m. the following morning, along a gently shelving stretch of sandy beach. They stranded in more or less a line with heads facing away from the sea and the animals were spread between a quarter and half a mile of beach. Number estimates range from I50 to 250 in the school and none was seen which did not come ashore. A few which were pushed out to sea returned fairly quickly and became stranded again. Length estimates state that the school contained small young about $3 \mathrm{ft}$ in length but were mostly about $8 \mathrm{ft}$ with some possibly up to Io $\mathrm{ft}$; however actual measurements do not appear to have been made. A considerable proportion (some writers state up to $50 \%$ :) were pregnant females and there was agreement that the foetuses were of similar size estimated as $2^{\prime} 6^{\prime \prime}$ to $3^{\prime} 0^{\prime \prime}$ and judged by appearance as near full term. A photograph of one foetus held up by a fisherman is consistent with the size estimate. The observations on foetuses and also of apparently new born young suggest a relatively circumscribed breeding period during spring.

No observations on stomach contents were reported but there were several reports of small thread-like worms " as a crawling mass in the heads. " These appear to have been common and resemble the report of Nakajima and Nishiwaki (1965) on the presence of many nematodes in the air sinuses of the skull.

The occurrence of these animals in a single school of $150-250$ and the report of another and larger school off Japan in I965 (Nishiwaki and Norris, I966) indicate that this is a schooling species, despite the isolated nature of each of the skulls received. A smaller group (estimated as about two dozen) has been reported by a fisherman (Mr. L. Elford) who collected specimens from the Crowdy Heads school and also obtained the Port Macquarie specimen. These were stranded at Diamond Head, a few miles from Port Macquarie and all were cut up and completely used for bait. Other local fishermen recognised that the size, colour pattern and head shape differed from the usual local dolphins and agreed with those at Crowdy Heads. They also report occasional sightings of similar schools at about the edge of the continental shelf along the neighbouring coast. It is therefore possible that $P$. electra is not particularly rare along the coast of northern New South Wales but that it is a species which normally remains some distance from land.

\section{External features}

The earliest representation of the external appearance of the electra dolphin is provided by Peale (I848) and is reproduced in True (I889).

The lateral view of the animal shows it to be darkly pigmented over most of the body, but showing a white patch midway between lower jaw and flipper and an elongated white ventral area extending from some way in front of the level of the 
anterior margin of the dorsal fin, to a level midway between dorsal fin and tail. There is indication of a white lower lip and lighter pigment around the eye.

The next figure of external appearance is that of Owen (I866), (his plates 5, fig. I and 7 , figs. I-5) with reference to L. fusiformis (a synonym). This reference is given only to emphasise the error in representation of the electra dolphin.

Goodwin (I945) reproduced the drawing made by Robert Cushman Murphy of an electra dolphin taken in the tropical Atlantic in I9I2. This drawing shows an absence of pigmentation around the mouth and on the throat, but no white area more posteriorly on the belly. A noteworthy feature is a ventrally projecting, long, low eminence in the post-anal region.

The photographs included in Nishiwaki and Norris (I965) best show the external form and pigmentation. These authors give a description of shape, particularly of the head, in connection with the erection of the genus Peponocephala to include $P$. electra, because of the absence of a well defined rostrum. The various pictures show the electra to be predominantly darkly pigmented. The white mouth area is conspicuous and in the ventral view the broad, unpigmented throat area behind the deeply pigmented lower jaw area, links up with the white patch seen in lateral view in Peale's and Goodwin's figures. At about the level of the flipper, the dark pigmentation extends from the side down to the mid ventral line. Behind this, a lenticular unpigmented area, extends from umbilicus to anus; this area again is the same area seen in restricted lateral view in Peale's figure.

\section{Specimens}

The following specimens were available for survey :-

No. Reg. No.

I B.M. (N.H.) I $844 \cdot$ IO.5.3

2 I $475 \mathrm{a}$

3 B.M. (N.H.) $358 \mathrm{a}$

4 W.A.M. 4798

5 A.M.N.H. 4300

6 B.M. (N.H.) I959.7.9.2.

7

8

9 B.M. (N.H.) I965.6.2.I
Type of Lagenorhynchus electra Gray, I846 Zool. Erebus \& Terror, I (Mammalia) 35, pl. I3. [ADULT in growth comparison]

Type of Delphinus fusiformis. Owen, I866 Trans. Zool. Soc. London, 6 : 22, pl. 5, fig. I, pl. 7 , figs. I-5.

Type of L. asia Gray, I846 Zool. Erebus \& Terror I (Mammalia) 35, pl. I4.

Salt marsh at Derby; W. Australia. Skull and skeleton.

$\sigma^{\top}$ found at $3^{\circ} 3^{\prime} \mathrm{N} 24^{\circ} 40^{\prime} \mathrm{N}$ in Atlantic. Goodwin 1945 J. Mammal 26 : 195.

đิ Hittadu Is., Addu Atoll. Gan Maldives. Skull and skeleton.

[ADOLESCENT in growth comparison]

New South Wales. No lower jaw. [JUVENILE in growth comparison]

New South Wales. Half skull, no lower jaw.

o Kahuku, Oahu, Hawaii

[NEWBORN in growth comparison]

ơ Hiratsuku. Nakajima \& Nishiwaki I965.

Sci. Rept. Whales Res. Inst. 19 : 9I-IO4.

(Readings taken from paper) 


\section{Osteological features}

The type of Lagenorhynchus electra Gray (Reg. No. I844.I0.5.3) is represented by a skull and lower jaw. The pointed conditions of the teeth indicate that the skull is of a mature but not aged specimen.

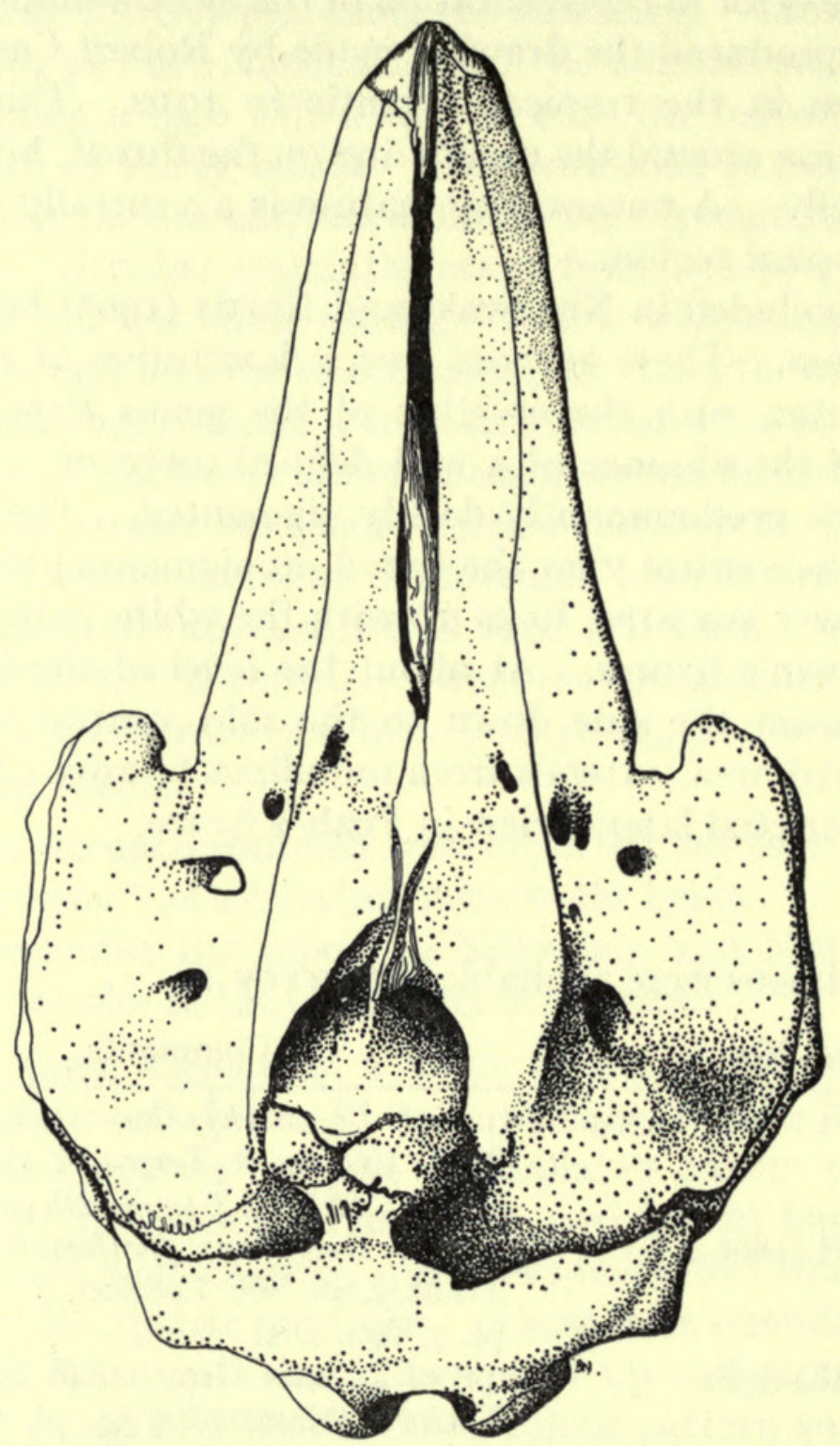

FIG. I. Peponocephala electra I844.10.5.3. type. Dorsal view, Orthographic projection.

In lateral view, the type skull is wedge-shaped, with the occipital condyle extending prominently from the base. The supraoccipital sweeps up to form the supraoccipital crest, which is connected to a prominent boss formed by the nasals, by a distinctive isthmus. The rostrum extends forwards from the cranium to form the apex of the wedge.

Rostrum. The rostrum is represented by the forward extension of the maxillae, premaxillae, vomer and mesethmoid cartilage beyond a line drawn between the caudal margin of the antorbital notches. In outline, dorsally (fig. I) starting from the antorbital notches, the rostrum is shallowly concave, almost immediately becoming extendedly convex ; it again becomes shallowly concave to about the mid-rostral 
length, where a convexity is initiated, which increases distally as the two maxillae approximate to each other. The proximal convexity is associated with a crest which is most obvious when viewed from the side.

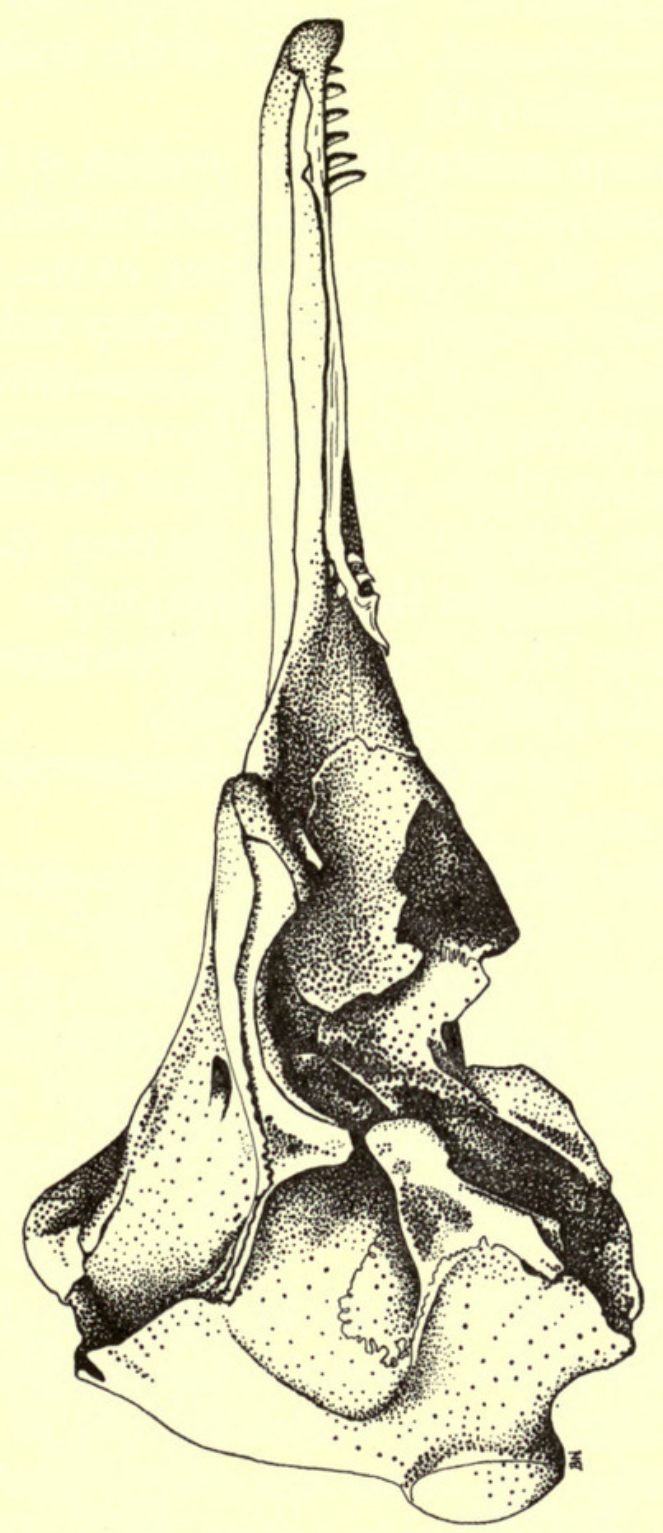

FIG. 2. P. electra $1844 \cdot$ I0.5.3. type. Lateral view. Orthographic projection.

Proximally the dorsal surface of the rostrum is flattened transversely, with its lateral maxillary margins slightly upturned (fig. 2). Further forward the rostrum becomes more convex, its regular contour being interrupted by a flexing of the medial borders of the premaxillae into a pair of crests so that with the cartilaginous extension of the nasal septum between them, they form a blunt keel. ${ }^{1}$

When the skull is viewed ventrally (fig. 3 ) it is seen that the distal portions of the rostrum are covered with dried palatine tissue, hiding the osteological features. Most of the ventral bony tissue is maxillary, but in the mid line, judging from other $P$. electra skulls, a sliver of vomer may be seen, with premaxillae exposed anteriorly to it.

1 There is a gap between the two premaxillae dorsally, extending the length of the rostrum, filled with a cartilaginous extension of the nasal septum. 
The tooth rows are short compared with the length of the snout; and they are ventrally directed. The alveoli are discrete.

There are sutures between palatines and maxillae, though laterally the palatines are squamous over the maxillae.

The pterygoid hamuli are damaged, the bone of the ventral region missing, exposing the sinuses of the pterygoid hamuli.

Cranial Region. This is represented by the portion of the skull that lies behind the line joining the caudal margins of the antorbital notches.

When viewed dorsally (fig. I), the cranial region of the skull is dominated by the large maxillary plates, whose margins show the deep indentations rostrally of the antorbital notches, and laterally they form the supraorbital margins. These supraorbital margins are nearly parallel with slight protrusions of the supraorbital processes of the frontals from under the maxillary plates, to form the pre- and postorbital processes. The margin runs obliquely backwards from the postorbital process until the line flows into the general shape of the cranium proper.

The essential rounded shape of the cranium is interrupted by the elevation formed by the posterior borders of the post-temporal fossae.

The cranium is traversed coronally by the supraoccipital crest, which forms a shallow anteriorly concave arc.

The maxillary plates which present by far the greatest area dorsally are spread widely over the frontals so that the latter are visible laterally only to the most limited extent. In their rostral portions the maxillary plates are roughly horizontal but curve upwards posteriorly toward the vertex of the skull, being separated there by the nasals. The maxillae extend to meet the base of the supraoccipital crest laterally, but medially in the area between the crest and maxillae, the frontals are exposed. There are conspicuous foramina in the maxillary plates, five on the right and three on the left.

The external nares are bounded caudally by the ossified mesethmoid, laterally for most of their extent by the internal margin of the premaxillae, but rostrally by the maxillae which have emerged on the dorsal surface of the skull. Cartilaginous elements between the maxillae and nasal septum are problematical in origin. The nasal region as a whole best illustrates the asymmetry of the skull.

The left premaxilla does not extend posteriorly to the nasal bone, whereas the right premaxilla extends half way along the right nasal bone.

The left premaxilla is altogether narrower than the right, to about the level of the premaxillary foramen.

The isthmus (formed by interparietal) of the nasal boss is situated to the left of the midline.

The left nasal is smaller than the right, the latter extending to the left of the midline of the skull.

Ventrally (fig. 3), the skull is divided by the two basicranial crests, with the basicranial trough running between them from the opening of the internal nares to the occipital condyles. To the side of the crest may be seen the supraorbital process of the frontal, with jugal (with the stump of the broken jugal arch) and sphenoids visible, together with their various associated foramina. Posterolaterally, the robust 
zygomatic process of the squamosal extends anteriorly toward the postorbital process, and with it forms an arch through which the temporal muscles pass. The external surface of the zygomatic process is rugose, with a definite depression within its margin ; the dorsal surface is smooth ; the ventral aspect is divided into articular and sinus areas.

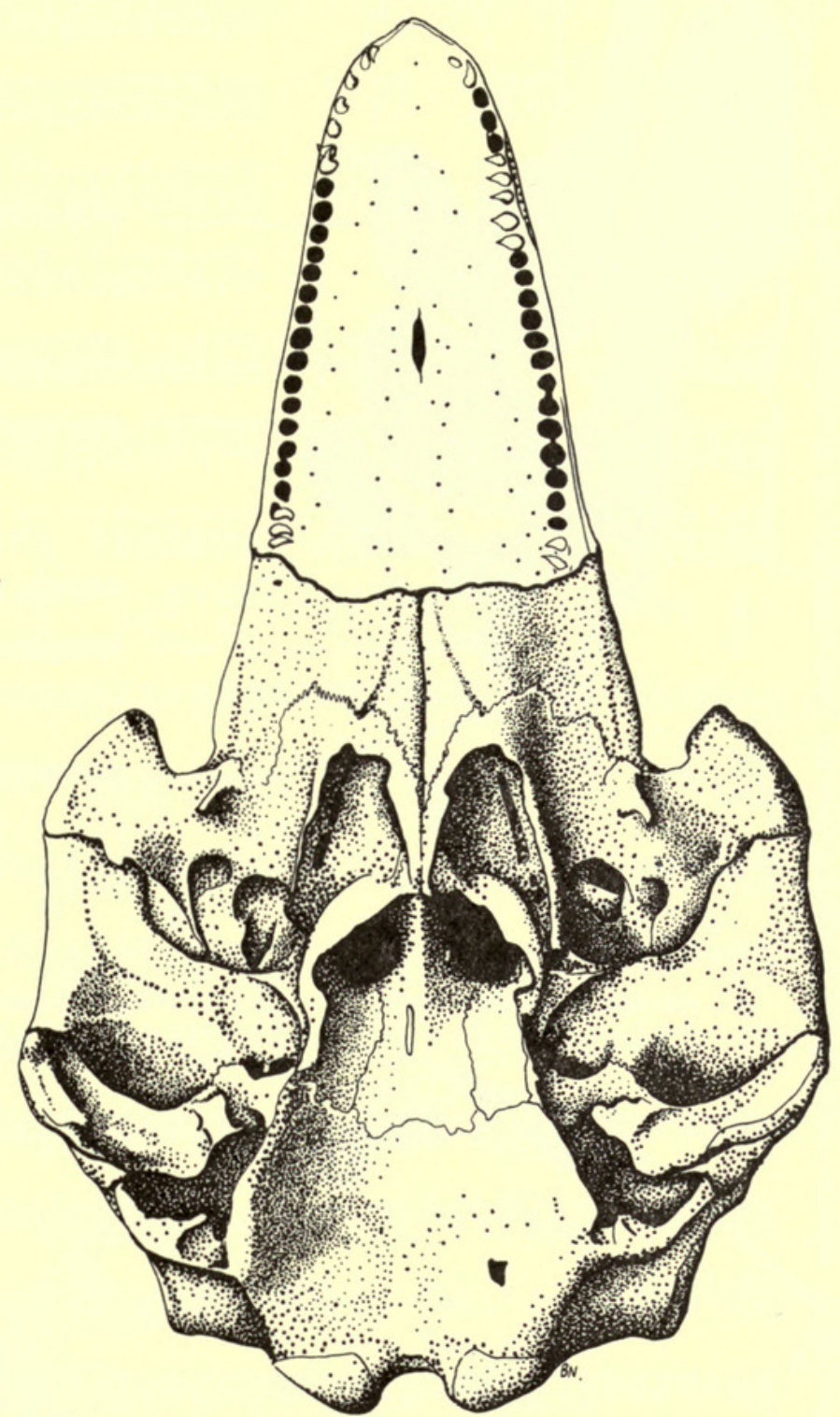

FIG. 3. P. electra I844.I0.5.3. type. Ventral view. Orthographic projection.

The bones of the ventral surface (figs. $3 \& 4$ ) of the skull give an indication of the extent of the air sinuses. On either side the pterygoid sinus extends medially as a pronounced excavation below the pterygoid portion of the basicranial crest ; the sinus extends into and fills the pterygoid hamulus. The middle sinus is situated on the ventral aspect of the zygomatic process and is extensive in area. The posterior sinus excavates the paroccipital process slightly. The orbital sinus is bilobed and this division is well demarcated by a distinct ridge on the supraorbital process of the frontal ; this evidence suggests that they approximate closer than do the two lobes of $L$. albirostris and L. obscurus respectively (Fraser \& Purves I960). The anterior lobe extends a little way anterior to the roots of the jugal arches. 


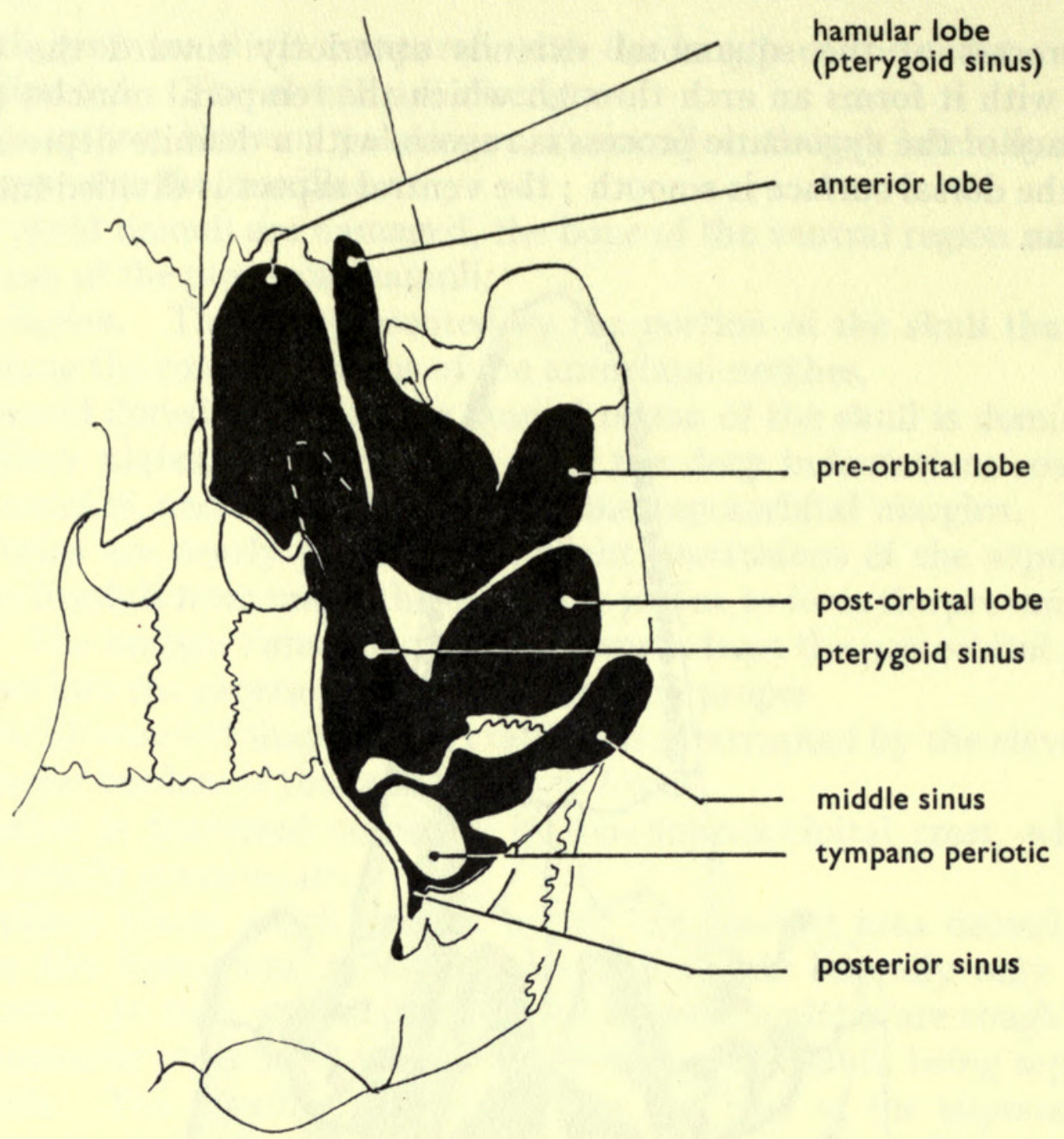

FIg. 4. P. electra. Sinus system. Semi-diagrammatic.

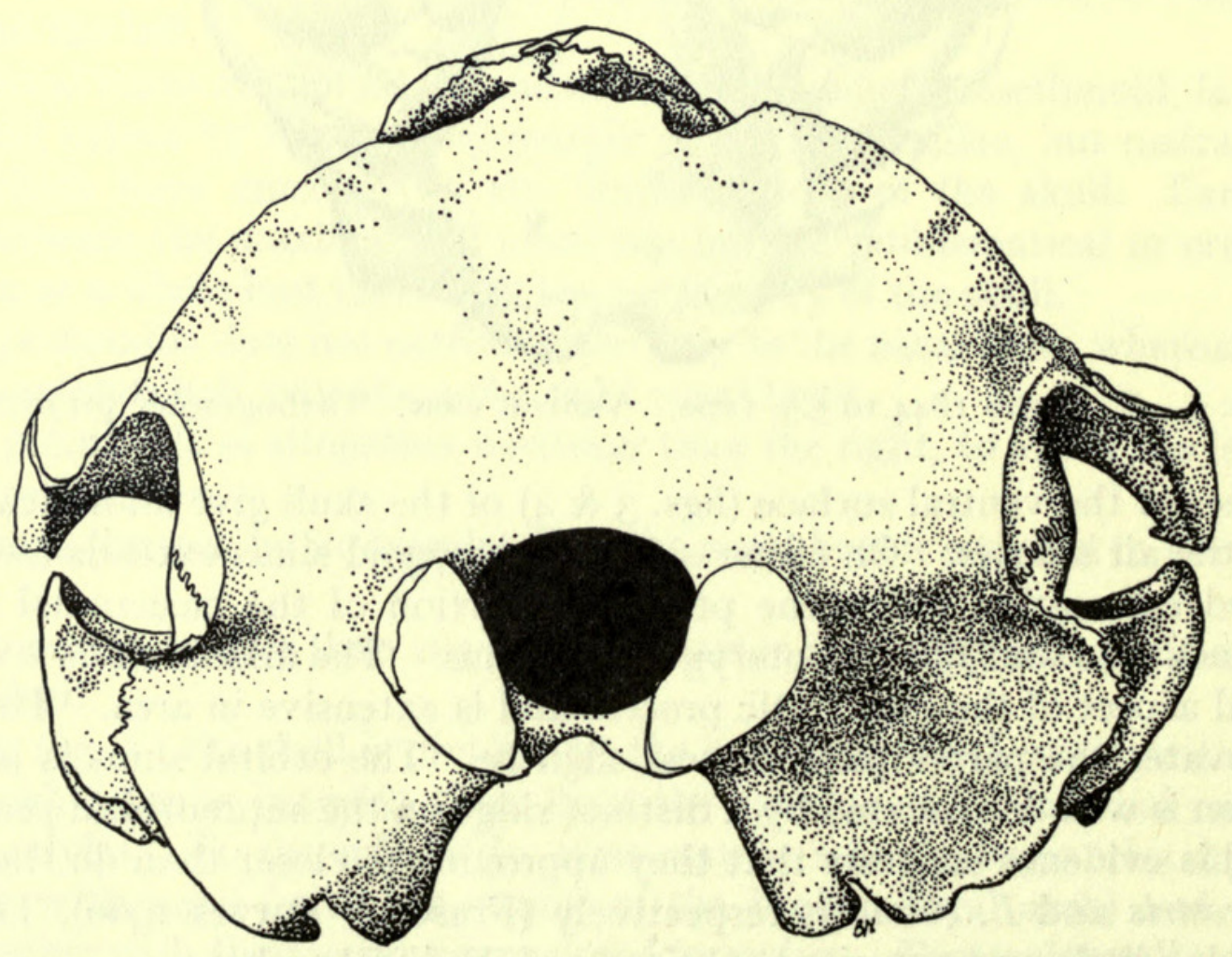

FIG. 5. P. electra I844.I0.5.3. type. Caudal view. Orthographic projection. 


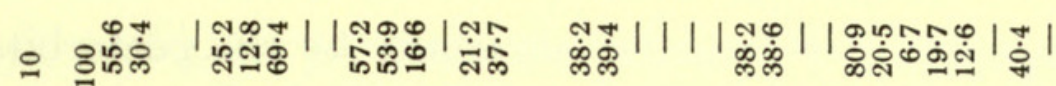

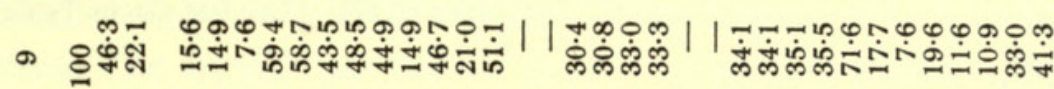

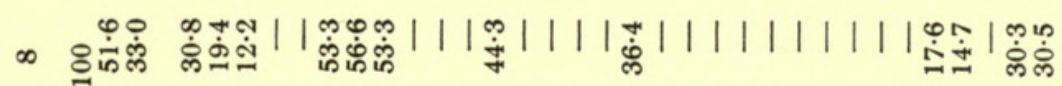

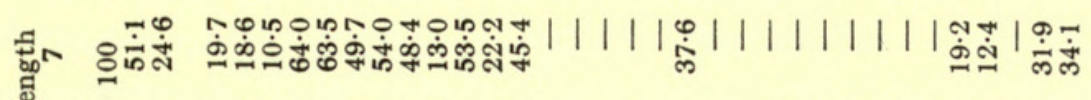

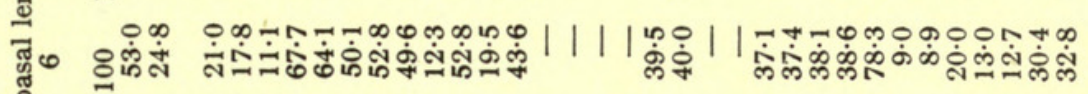

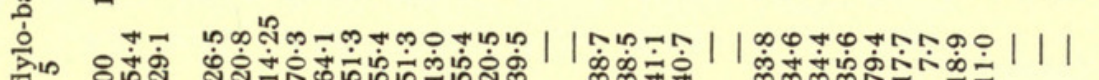

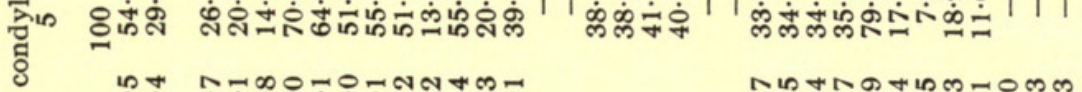

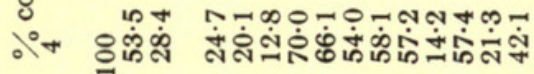

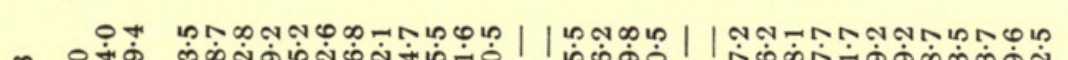

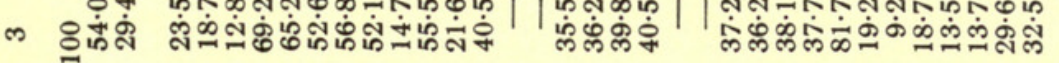

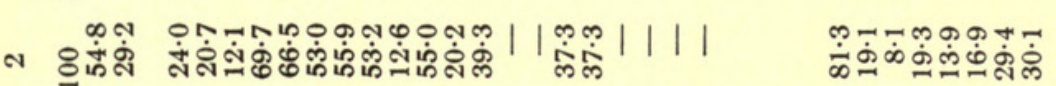

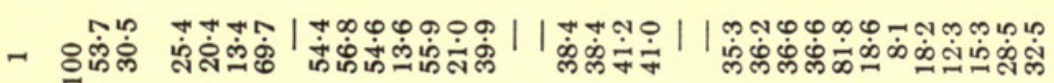

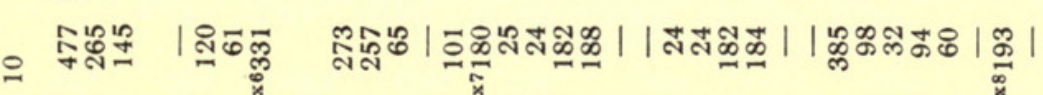

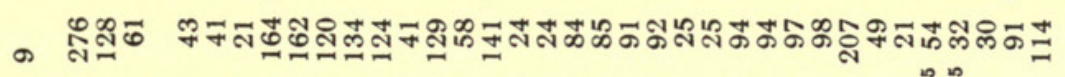

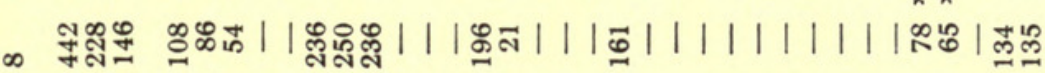

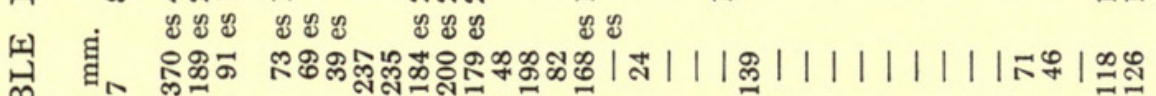
घ

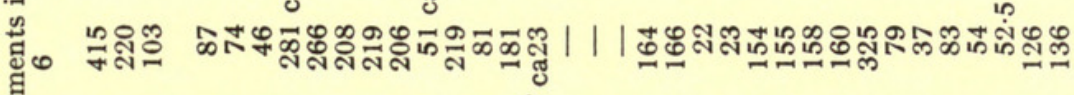

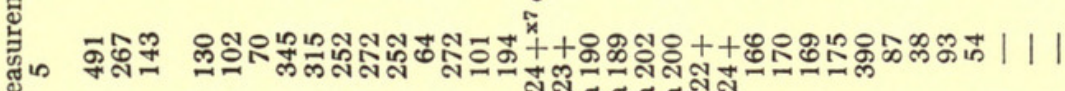

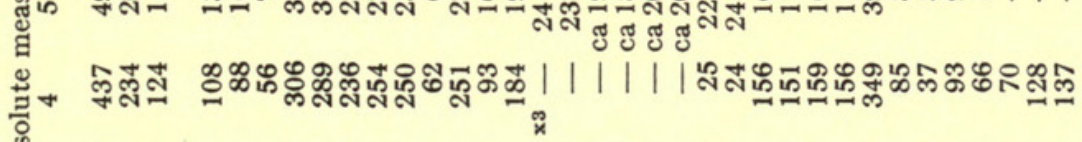

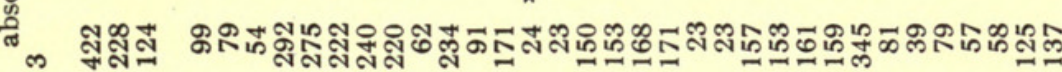

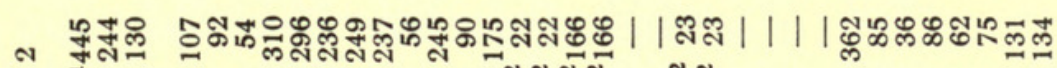
ห.

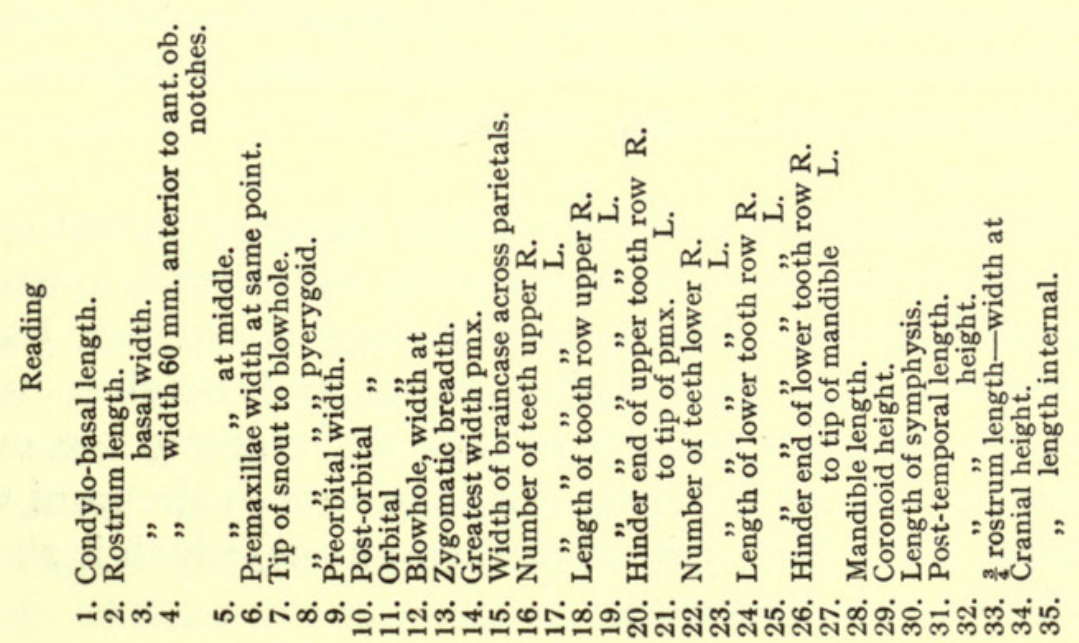

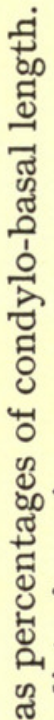

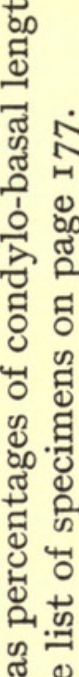

要

. 옹

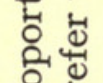

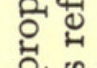

का o

벌

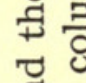

藏界

क्षे

के "ृ

R.

넝

苛

党

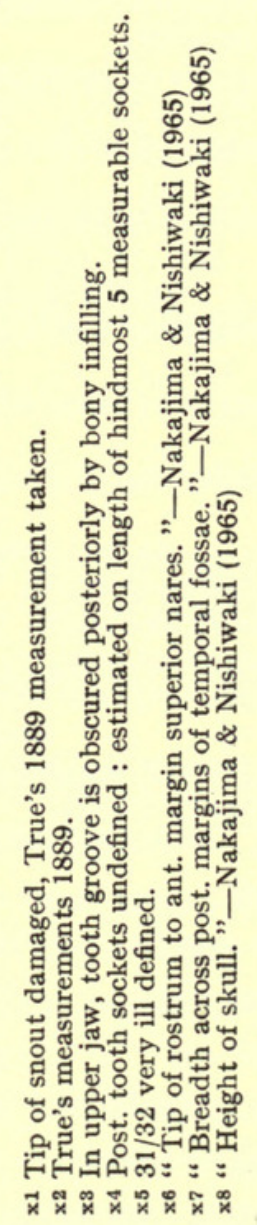


The post-temporal fossa (fig. 2) is bounded anteriorly by the postorbital process which is contained as a ridge of the exoccipital ; posteriorly the fossa is bounded by a ridge between parietal and exoccipital.

\section{TABLE 2}

I. Condylo-basal length.

2. Rostrum length.

3. ", basal width.

4.,$\quad$ width $60 \mathrm{~mm}$. anterior to ant. ob. notches.

5. , , , at middle.

6. Premaxillae width at same point

7. Tip of snout to blowhole.

8. , , , , , pterygoid.

9. Preorbital width.

ro. Post-orbital ,,

II. Orbital

I2. Blowhole, width at

I3. Zygomatic breadth.

I4. Greatest width pmx.

I5. Width of braincase across parietals

I6. Number of teeth upper R.

I7. , , , , , L.

I8. Length of tooth row upper R. I04.0 $94 \cdot 9 \quad 87 \cdot 7 \quad-\quad 97 \cdot 9 \quad-\quad-\quad-\quad 59 \cdot 6$

19. ", " ", ", L. I04.0 $94.989 .5-97.4-60.3$

2o. Hinder end of upper tooth

2r. to tip of pmx.
22. Number of teeth lower R.

23. , , , , L.

24. Length of lower tooth row $R$

26. Hinder "end of lower ", "ooth

27. to tip of mandible

28. Mandible length.

29. Coronoid height.

30. Length of symphysis.

31. Post-temporal length.

32. , , height.

33. $\frac{3}{4}$ rostrum length-width at

34. Cranial height.

35. " length internal.

\begin{tabular}{|c|c|c|c|c|c|c|c|c|}
\hline & & & $\%$ & f parie & tal wic & & & \\
\hline & 2 & & 4 & 5 & 6 & 7 & x18 & 9 \\
\hline $260 \cdot 6$ & $254: 3$ & $246 \cdot 7$ & 237.5 & $253 \cdot I$ & $229: 3$ & $220 \cdot 3$ & 225.5 & 195.7 \\
\hline $140 \cdot 0$ & 139.4 & 133.3 & $127 \cdot 2$ & $137 \cdot 6$ & 121.5 & 112.6 & 116.3 & 90.8 \\
\hline 79.4 & $74 \cdot 3$ & 72.5 & $67 \cdot 4$ & 73.7 & $56 \cdot 9$ & $54^{\cdot 2}$ & 74.5 & $43 \cdot 3$ \\
\hline $66 \cdot 3$ & $6 \mathrm{I} \cdot 2$ & $57 \cdot 9$ & $58 \cdot 7$ & $67 \cdot 0$ & $48 \cdot I$ & 43.4 & $55 \cdot I$ & $30 \cdot 5$ \\
\hline $53 \cdot I$ & $52 \cdot 6$ & $46 \cdot 2$ & $47 \cdot 8$ & $52 \cdot 5$ & 40.9 & $4 \mathrm{I} \cdot \mathrm{I}$ & $43 \cdot 9$ & $29 \cdot I$ \\
\hline $34 \cdot 8$ & $30 \cdot 9$ & $3 I \cdot 6$ & $29 \cdot 7$ & $36 \cdot I$ & 25.4 & $23 \cdot 2$ & 27.5 & I 4.9 \\
\hline $\mathrm{I} 8 \mathrm{I}$ & I $77 \cdot 2$ & I 70.8 & $166 \cdot 3$ & I 77.8 & $155^{\circ} 2$ & $\mathrm{I}_{4} \mathrm{I} \cdot \mathrm{O}$ & - & 116.3 \\
\hline 780 & I69.I & I60.8 & I $57^{\circ} \mathrm{O}$ & I $62 \cdot 4$ & $147^{\circ} \mathrm{O}$ & I $39^{\circ} 9$ & 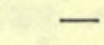 & $\mathrm{II}_{4} 49$ \\
\hline $\mathrm{I} 4 \mathrm{I} \cdot 8$ & 134.9 & I29.8 & $128 \cdot 2$ & $129^{\circ} 9$ & 114.9 & 109.5 & 120.4 & $85 \cdot 1$ \\
\hline $148 \cdot 0$ & $142 \cdot 3$ & 140.4 & 138.0 & $140 \cdot 2$ & $12 \mathrm{I}^{\circ} \mathrm{O}$ & II ${ }^{\prime}$ I & $127 \cdot 6$ & 95.0 \\
\hline $142 \cdot 3$ & 135.4 & 128.6 & 135.8 & 129.9 & 113.6 & 106.5 & 120.4 & $87 \cdot 9$ \\
\hline 35.4 & $32 \cdot 0$ & $36 \cdot 2$ & 33.8 & $32 \cdot 9$ & $28 \cdot 2$ & $28 \cdot 6$ & . & $29 \cdot I$ \\
\hline 145.7 & $I_{4} 0^{\circ} \cdot \mathrm{I}$ & I36.9 & 136.8 & $140 \cdot 2$ & $12 I^{\circ} 0$ & $\operatorname{II} 7^{\circ} 9$ & - & 9I. 5 \\
\hline $54^{\circ} 9$ & $5 \mathrm{I} \cdot 4$ & $53 \cdot 2$ & $50 \cdot 5$ & $52 \cdot I$ & $44 \cdot 7$ & $4^{8 \cdot 8}$ & & $4 I \cdot I$ \\
\hline & 100 & 100 & 100 & IOO & I00 & I00 & I00 & 100 \\
\hline
\end{tabular}

- I04.I $90.6-64.5$

$\begin{array}{lllll}\text { - IO3.I } & 91 \cdot 7 & 82.7 & 82 \cdot 1 & 65.2\end{array}$

L. $\begin{array}{lll}107 \cdot 4 & -\quad 98 \cdot 9 \\ 106 \cdot 9 & -\quad 100\end{array}$

$92 \cdot 0 \quad-\quad 9 \mathrm{r} \cdot 8 \quad 84 \cdot 3 \quad 85 \cdot 6 \quad 85 \cdot \mathrm{I}-\quad-66 \cdot 7$

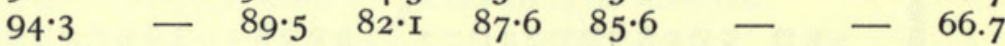

R. $95.4-94 \cdot \mathrm{I} \quad 86.4 \quad 87 \cdot \mathrm{I} .87 \cdot 3 \quad-\quad-68.8$

L. $95.4-93.0 \quad 84.8 \quad 90.288 .4$ - $\quad$ - 69.5

2I3.I 206.8201 .8 I 89.7 20I.0 I80.0 —

$\begin{array}{lllllll}48 \cdot 6 & 48 \cdot 6 & 47 \cdot 4 & 36 \cdot 7 & 44 \cdot 8 & 43 \cdot 6 & \text { - }\end{array}$

$\begin{array}{lllllllll}2 \mathrm{I} \cdot \mathrm{I} & 20 \cdot 6 & 22 \cdot 8 & 2 \mathrm{O} \cdot \mathrm{I} & \mathrm{I} 9 \cdot 6 & 20 \cdot 4 & - & \mathrm{I} 4 \cdot 9\end{array}$

$\begin{array}{lllllllll}47 \cdot 4 & 49 \cdot 1 & 46 \cdot 2 & 50 \cdot 5 & 47 \cdot 9 & 45 \cdot 8 & 42 \cdot 3 & 39 \cdot 8 & 38 \cdot 3\end{array}$

$\begin{array}{lllllllll}32 \cdot 0 & 35 \cdot 4 & 33 \cdot 3 & 35 \cdot 9 & 27 \cdot 8 & 29 \cdot 8 & 27 \cdot 4 & 33 \cdot 2 & 22 \cdot 7\end{array}$

$\begin{array}{llllll}40 \cdot 0 & 42 \cdot 9 & 33.9 & 38 \cdot 0 & 29 \cdot 0 & -\end{array}-2 \mathrm{I} \cdot 3$

$\begin{array}{llllllll}74 \cdot 3 & 74 \cdot 9 & 73 \cdot 1 & 69 \cdot 6 & 69 \cdot 6 & 70 \cdot 2 & 68 \cdot 4 & 64 \cdot 4\end{array}$

$\begin{array}{llll}75 \cdot 1 & 75 \cdot 0 & 68 \cdot 9 & 80 \cdot 8\end{array}$

Skull dimensions of $P$. electra and their proportions as percentages of parietal width.

The numbers at the head of the column refer to the list of specimens on page 177 .

x1 Percentages are to estimated measurement of width of brain case.

The caudal aspect of the skull (fig. 5) is dominated by the great extent of the fused occipital bones. The general contour is interrupted by the occipital condyles with the oval foramen magnum between. The general outline is circular, but is interrupted by the basioccipital crests, paroccipital crests and notches, nasal boss, zygomatic processes and the posterior margins of the post temporal fossae.

Lower Jaw. The lower jaw (fig. 6) is robust, the long axes of the rami making an acute angle with each other where they join at the symphysis, which is short. (The two rami are fused together in this specimen). 
The upper and lower margins of the rami are almost parallel up to the hinder end of the tooth row, where they diverge, the upper margin being produced into a low crest between the hindmost tooth and coronoid process. From the coronoid process the margin extends obliquely and rather irregularly to the condyle.

Slightly anterior to the level of the mandibular foramina, the profile of the jaw is produced into a keel, which is continued distally into the anterior profile of the jaw.

The symphysis is short and in ventral view the prow of the jaw is evenly rounded to each ramus anterior to the keels.

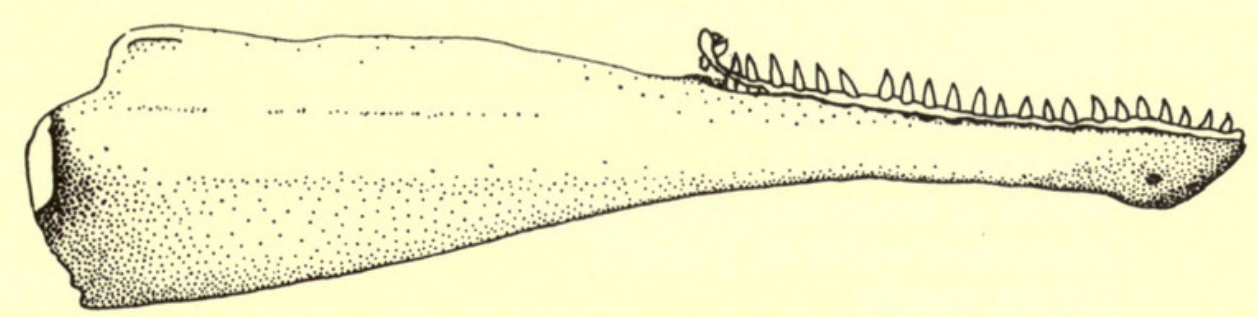

FIG. 6. P. electra I844.I0.5.3. type. Lateral view right mandible. Orthographic projection.

The tooth rows are again short compared with the length of the jaw, the teeth sitting in discrete alveoli. The proximal teeth are upright in attitude, but proceeding distally they assume an increasingly lateral splay. The crowns of the teeth are separated by a distance of approximately the basal diameter of the teeth.

The dimensions of the type skull and of other available specimens are given in Tables I \& 2.

\section{GROWTH OF THE SKULL}

(a) Quantitative Discussion. The changes observed with growth are demonstrated quantitatively. The conventional use of condylobasal length as a base for the comparison of other measurements was discarded in favour of parietal width, following an earlier paper by Fraser and Noble (I968).

It is generally accepted that increase in the size of the brain levels off at a comparatively early stage in the animal's life. The similarity of cranial size in the juvenile and adult indicates conformity to this growth pattern.

To determine the rates of growth of the various parts of the skull, values of the various measurements were plotted against their respective parietal widths on a double logarithmic scale. It may be taken that the rates of growth of the various parts, relative to parietal width, satisfy the equation $y=b x^{\mathbf{k}}$. Where $x$ is the parietal width, $y$ the length of the part, $b$ the fractional coefficient (the value of $y$ when $x=\mathrm{I}$ ), and $k$ the growth coefficient. Calculated values are shown below (Table 3 ). Values of $k$ over unity indicate an increasing rate of relative growth and those less than unity the converse ; i.e. positive and negative heterogoniety respectively.

The skull of the new-born animal is essentially a brain box with diminutive rostrum, supraorbital and zygomatic processes. The growth of the skull is predominantly of these extensions from the brain box. 


\section{TABLE 3}

\section{Peponocephala electra}

Table of growth coefficients for various parts of the skull

\begin{tabular}{clc} 
Reading No. & \multicolumn{1}{c}{ Measurement } & $\begin{array}{c}\text { Growth } \\
\text { coefficient }\end{array}$ \\
I & Condylo basal length : & $\mathbf{I} \cdot 85$ \\
2 & Rostrum : length : & $2 \cdot 35$ \\
3 & Rostrum : basal width : & $2 \cdot 90$ \\
4 & Rostrum : width 6o mm. anterior to ant-orbital notches : & $3 \cdot 50$ \\
5 & Rostrum : width at middle : & $3 \cdot 00$ \\
9 & Preorbital width : & $2 \cdot 60$ \\
Io & Postorbital length : & $2 \cdot 40$ \\
I3 & Zygomatic breadth : & $2 \cdot 70$ \\
I5 & Width of braincase across parietals : & $\mathbf{I}$ \\
33 & Rostrum : width at $\frac{3}{4}$ length : & $3 \cdot 20$ \\
34 & Cranial height : & $\mathbf{I} \cdot 45$ \\
35 & Cranial length internal : & $0 \cdot 725$
\end{tabular}

The increase of the condylobasal length is by the growth of two components, rostral and cranial. It will be seen from Table 3 that the contribution of rostral length $(2 \cdot 35)$ to total length is much greater than is cranial length $(0 \cdot 725)$.

In the rostrum itself growth can be regarded as taking place two-dimensionally, and the table indicates that length, although prominently positively heterogonic is at a lower rate than its lateral expansion. The lateral expansion is not uniform for the whole rostrum. Reading No. 4 is an expression of the lateral expansion that takes place in the basal portion of the rostrum, which is at a lower rate than at the middle of the beak. Towards the tip of the snout (Reading 33) the coefficient indicates a relatively high rate. The interaction of these growth rates is expressed in the shape of the adult rostrum.

In the newborn, the preorbital width is considerably less than the postorbital width $(5 \%)$, and the projections, which develop laterally, are all of less dimension than the parietal width. The reversal of this condition with age is achieved by the faster growth of these parts compared with the expansion of the brain box.

Development of the postorbital and zygomatic processes result in the enlargement of the post-temporal fossa. In the new-born, this aperture, through which the temporal muscle passes, is small and subtriangular ; by the growth of the zygomatic and postorbital processes it becomes rounder and is visible in the caudal aspect of the skull of the adult.

The coefficients showing development of the brain box (reading $15,34,35$ ) indicate a lower rate than for any of the other dimensions considered. But the coefficients of growth throughout the animal's life do not take into account the established fact that brain growth is, in the main, achieved in youth and because of the limitation in available young specimens it is not possible to present coefficients for this rapid phase in the growth of the brain.

(b) Topographical Description. Figures 7-II. To demonstrate the changes in the skull with age, four skulls were selected which gave a range of size and development 
which could be accepted as indicative of increasing age. The skulls chosen were as follows :-

newborn. Reg. No. I965.6.2.I. Known to be newborn.

juvenile. The more complete New South Wales specimen. Chosen on its size and stage of development on generally accepted criteria, such as sutures and occipital crest development.

adolescent. I959.7.9.2. Chosen on its condylobasal length, small size of ossified scapula and non-fusion of vertebral epiphyses.

adult. $\quad$ I844.I0.5.3. The type of L. electra Gray. Chosen on condylobasal length and vertebral and scapular development of a skeleton with skull of comparable size and development (W.A.M. No. 4798).

\section{General Cranial Shape}

\section{Cranial Region}

Newborn : The essential cranial shape is obvious, being smoothly rounded from

No. 9* foramen magnum to nasals. The lateral development of supraorbital processes, maxillary plates, and zygomatic processes is slight ; and the supraoccipital crest is not developed. The greatest width of the skull is between the parietals.

Juvenile : The basic shape of the cranium has already become obscured by the No. 7 extension of the supraorbital and zygomatic processes, incipient post-temporal fossa and occipital crest development. The greatest width is between the zygomatic processes.

Adolescent : Approximately as in the adult, but the occipital crests are considerNo. 6 ably less developed.

Adult : The primary cranial shape is very obscured by the growth of these No. I various features.

\section{Sutures}

Newborn : All the visible sutures are unfused.

Juvenile : The only sutures that are fused are those between the occipital bones ; there is partial fusion of the parietals with the supraoccipital ; the interparietal is fused with the supraoccipital.

Adolescent : There is no significant change from the condition in the juvenile. There is indication however of the beginning of fusion of the nasal portion of premaxillae with maxillae.

Adult : Nearly every suture has either fused or is showing indication of fusion. The exceptions are: the squamosals which are very loosely joined to the skull ; frontals with maxillae ; jugals with frontals and maxillae; nasals with interparietal; vomer with basisphenoids and basioccipital.

* numbers refer to the list on page $\mathrm{I} 77$. 


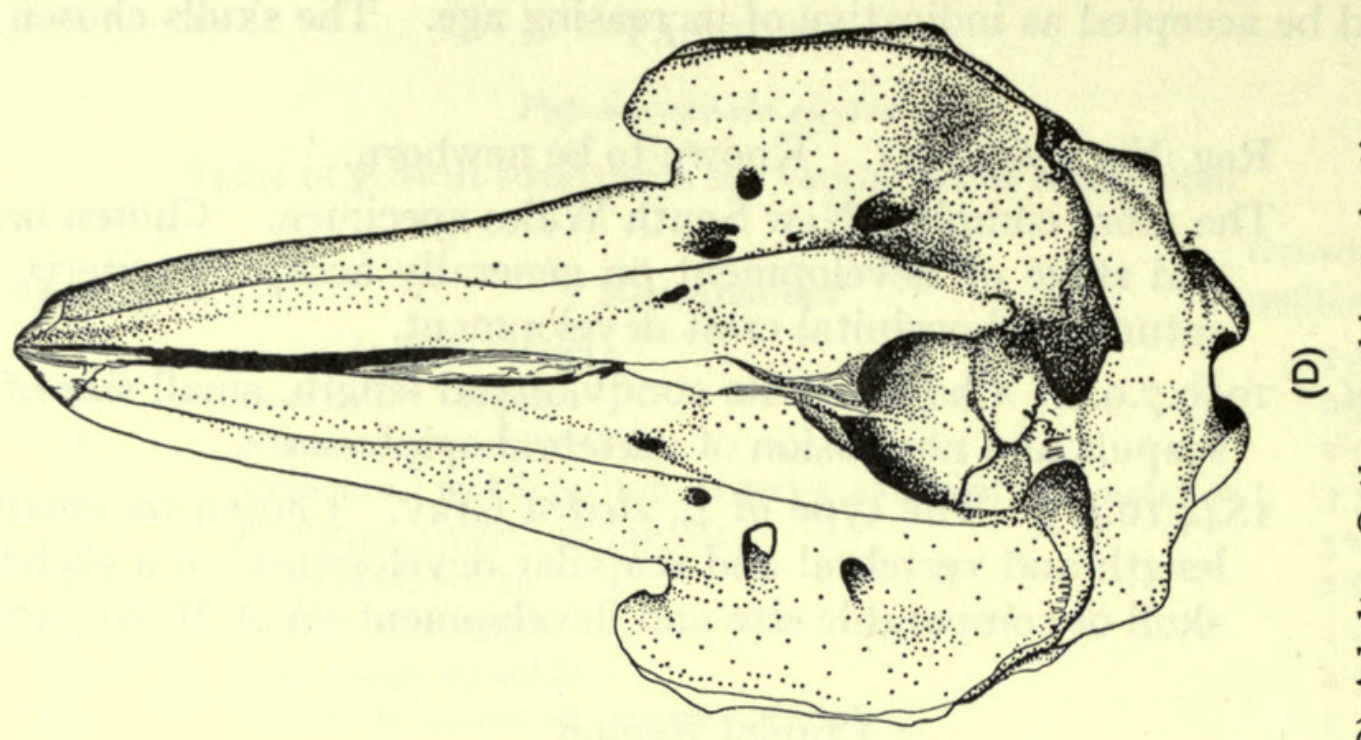

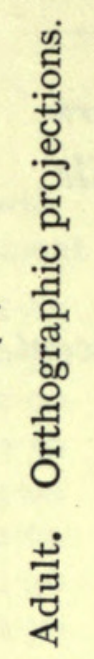

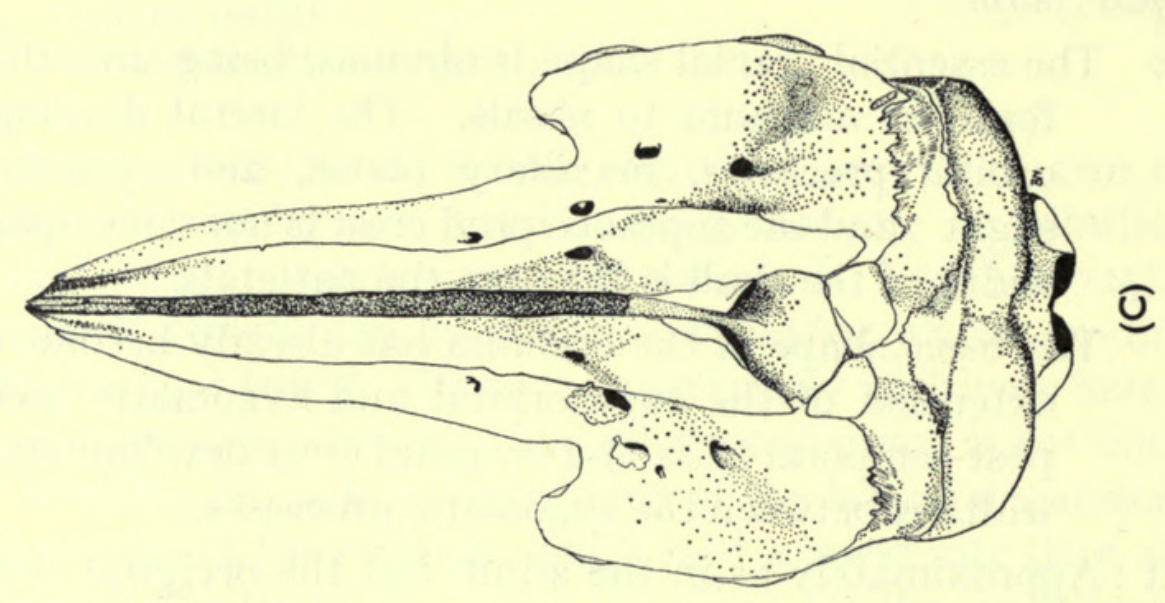

$\widehat{\mathrm{e}}$

ثี

遇

원

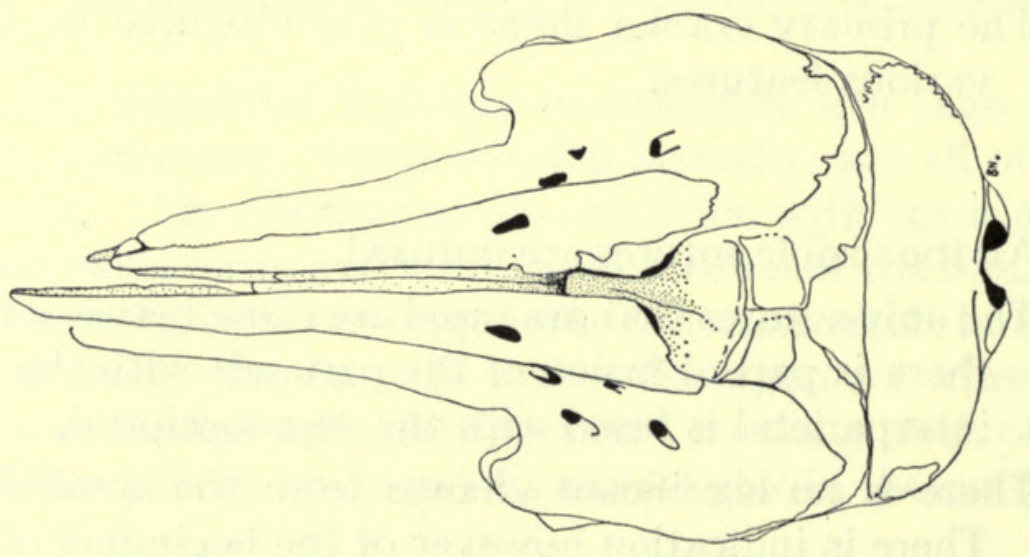

क व

2

\}

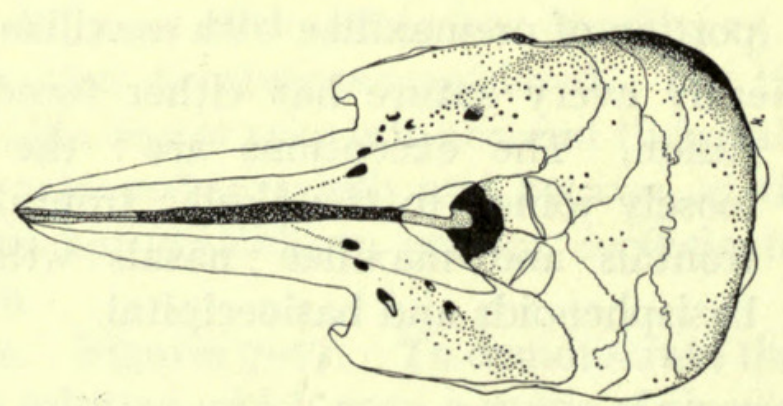

$\S$ 
(A)

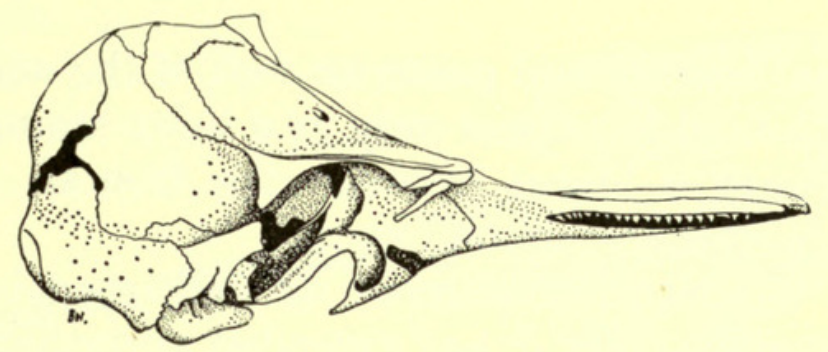

(B)

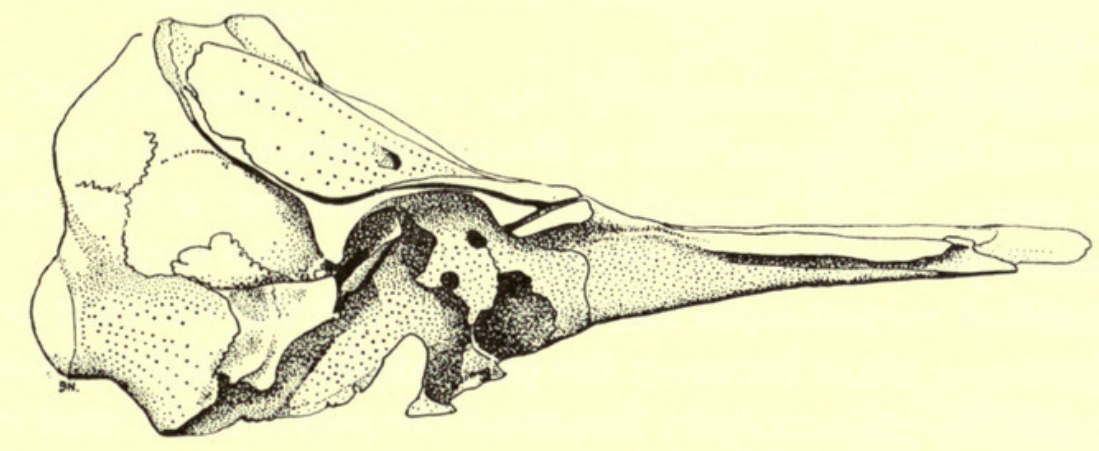

(C)

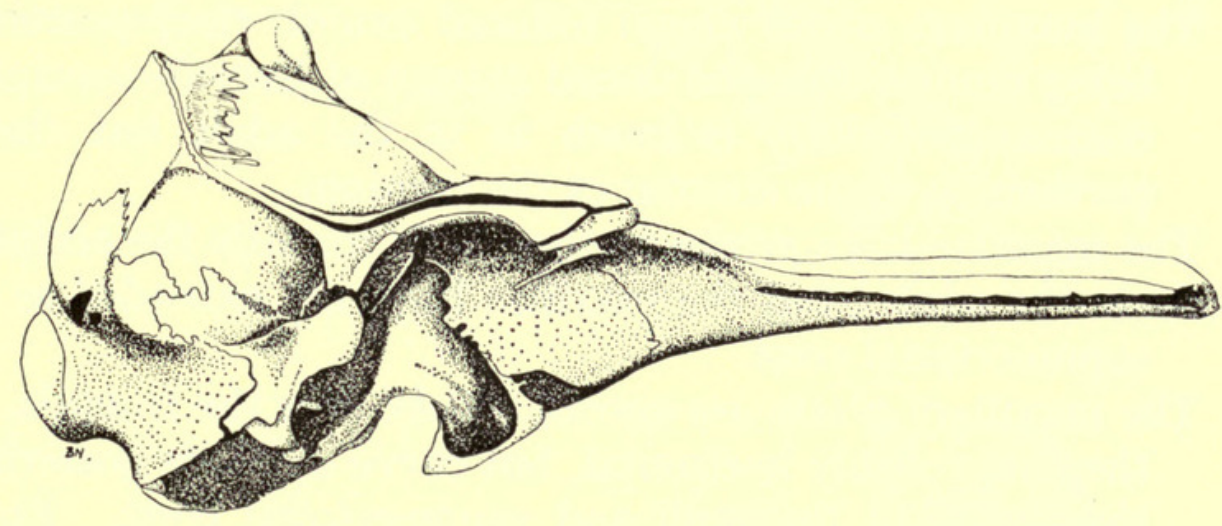

(D)

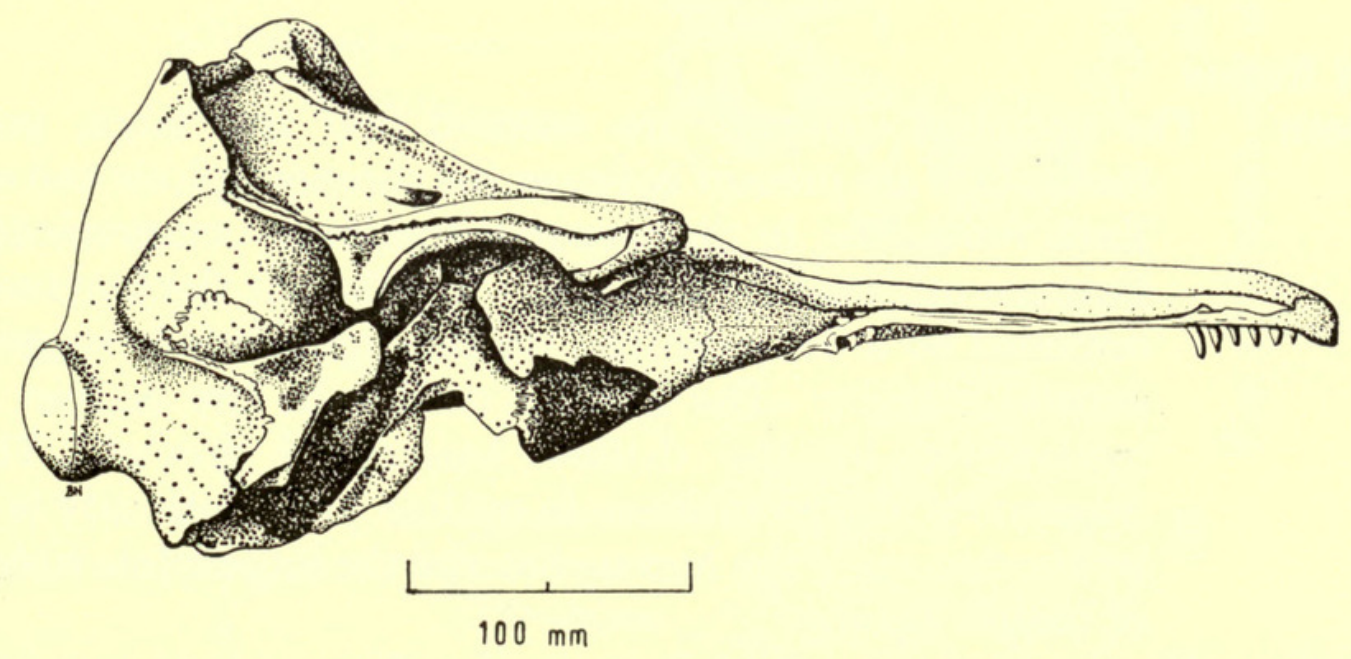

FIG. 8. Lateral view of skulls of P. electra ; (A) Newborn, (B) Juvenile, (C) Adolescent, (D) Adult. Orthographic projections. 


\section{Development of the mesethmoid}

The mesethmoid forms the basal septum and posterior wall of the narial passage.

Newborn : The ossified mesethmoid is present only as a bony stump projecting posterodorsally into a hiatus between the frontals. The nasal septum is composed of soft tissue.

Juvenile : The mesethmoid is considerably more ossified, covering over the hiatus in the cranium, and it has extended appreciably over the frontals. The nasal septum is represented by a bony ridge which has not developed to the level of the dorsal surface of the premaxillae.

Adolescent : The mesethmoid now extends up to make contact with the nasals. The ossified nasal septum is above the level of the lateral borders of the nares. This forward extension however is still restricted and has not yet reached the rostral portion of the skull.

Adult : The ossified mesethmoid has extended into the rostrum and is seen as a flattened plate between the premaxillae. Slightly anterior to the level of the premaxillary foramina the septum becomes cartilaginous and continues so to the rostral tip.

\section{Maxillary Plate}

Newborn : The maxillary plates are of reduced extent, their posterior margins being remote from the dorsal margin of the supraoccipital. Their contour anteriorly is much as in the adult but their elevated portions have the contour of the cranium.

Juvenile : The maxillae have grown further back towards the occipital crest.

Adolescent : As in the adult ; but the maxillae have not extended as near to the supraoccipital crest.

Adult : The maxillary plates are spread widely over the frontals. Rostrally they are roughly horizontal, but curve upwards posteriorly toward the vertex of the skull and supraoccipital crest. Frontal is exposed medially between the maxillae and the crests.

\section{Occipital Region}

Newborn: The occipital elements are unfused and two large, posterolateral fontanelles are present between the supraoccipitals and exoccipitals. Each fontanelle, in the prepared specimen, communicates with the foramen magnum by a fissure. On the left the fontanelle is partly occluded by a bony centre ; on the right, this is suggested by the sutural margin. The general outline of the occiput is circular, interrupted by the shallow basicranial groove. The foramen magnum is almost piriform in outline ; its continuity is interrupted by the fissures of the fontanelles and the incomplete fusion ventrally of basioccipital,

Juvenile : The supra- and exoccipitals are fused to a great extent. There is a bony insert, which is unfused on the left, in a similar position to 


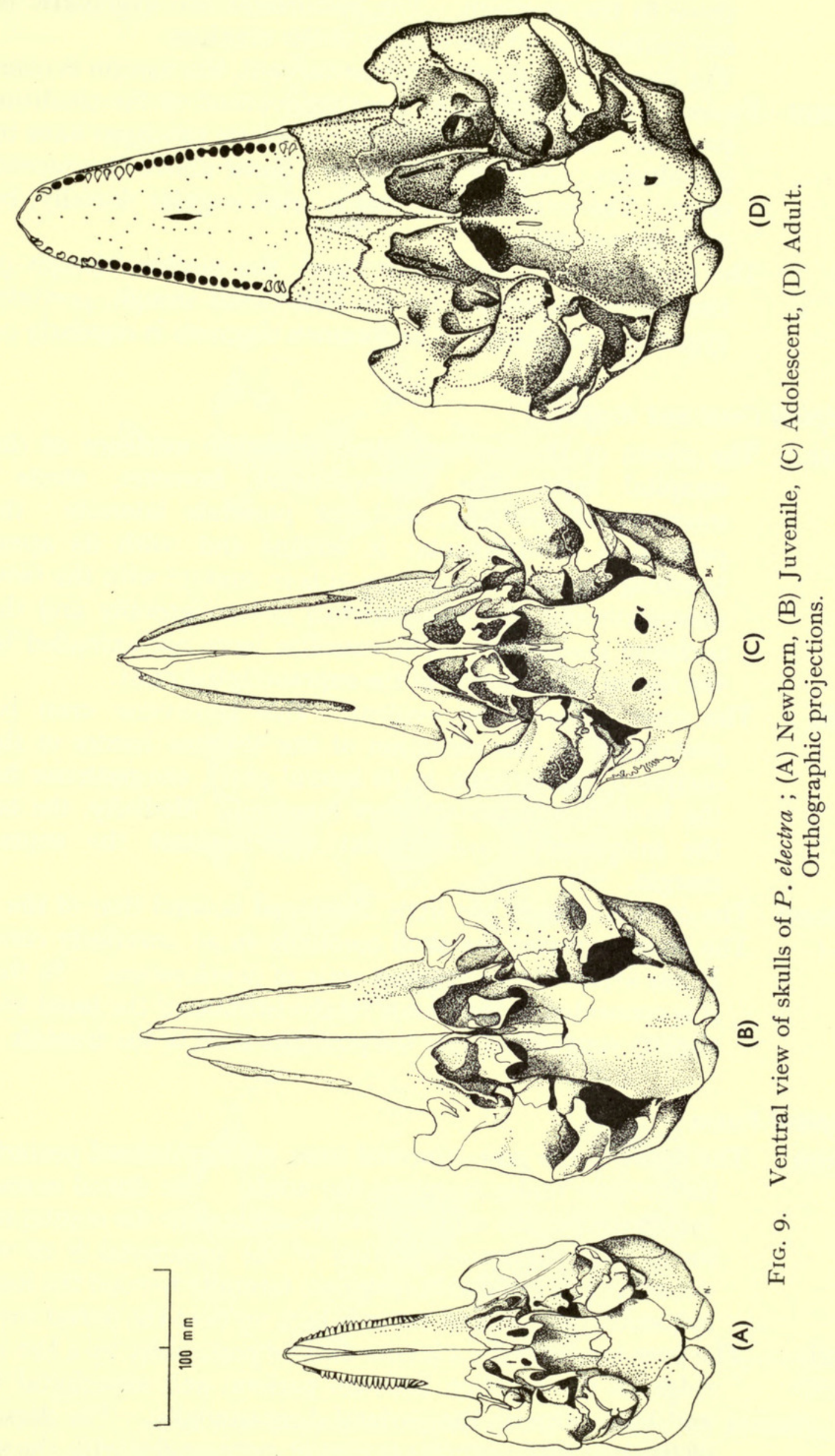


those in the newborn. The postorbital and zygomatic processes are visible beyond the outline of the cranium.

The foramen magnum is subpentagonal, the margin is complete.

Adolescent : Fusion of the sutures is not greatly advanced on the condition in the juvenile. The postorbital and zygomatic processes have increased prominence, and the nasals now appear above the supraoccipital crest. The foramen magnum is more angular dorsally, but more rounded ventrally.

Adult : The occipitals are completely fused, the outline, though generally circular is interrupted by the basicranial trough, postorbital and zygomatic processes. The foramen magnum is regularly oval.

\section{Supraoccipital Crest and Region}

Newborn: The crown of the newborn skull shows no evidence of the supraoccipital crest. The supraoccipital, however, abuts on the interparietal medially, and the parietals laterally; the interparietal is sub-triangular in outline and, with its apex almost touching the right nasal bone, it is in contact with the two frontals anterolaterally, the two parietals posterolaterally and the supraoccipital posteriorly. The maxillae have not extended back into the region of formation of the supraoccipital crest.

Juvenile : The crest is becoming evident. This transverse crest is formed posteriorly by the elevation of the anterior border of the supraoccipital. Anteriorly, in its lateral parts, the posterior borders of the frontals and parietals are involved. Medially, the borders of the interparietal and frontal abut against the supraoccipital margin.

Adolescent : The crest is defined but little developed beyond that of the juvenile. Adult : The crest traverses the skull coronally in an anteriorly concave arc. It has attained an advanced state of development. In the midline it is connected to the nasals by the isthmus of the nasal boss. It is slightly convoluted over the posterior limit of the frontals.

\section{Post-temporal Fossa}

Newborn : The limits of the post-temporal fossa are not defined posteriorly, but its anterior limits are as in the adult. The dorsal surface of the zygomatic process makes an acute angle with the cranial wall of the fossa. The squamous portion of the squamosal is of very little extent. The parietal bone bulges laterally beyond the limits of the zygomatic process and extends high up onto the dorsal surface.

Juvenile : The post-temporal fossa is now defined posteriorly by a low ill-defined ridge on the junction between parietal and exoccipital ventrally, and by a ridge on the parietal dorsocaudally. The dorsal surface of the zygomatic process is now at right angles with the skull ; the 
(A)

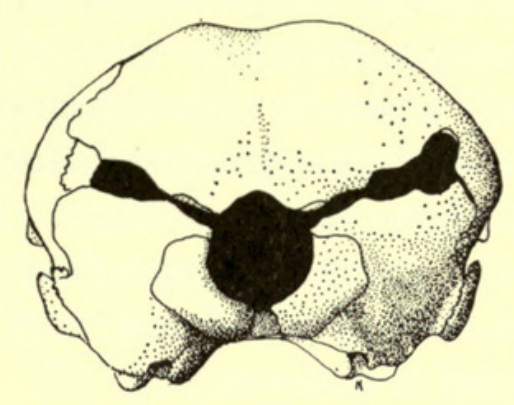

(B)

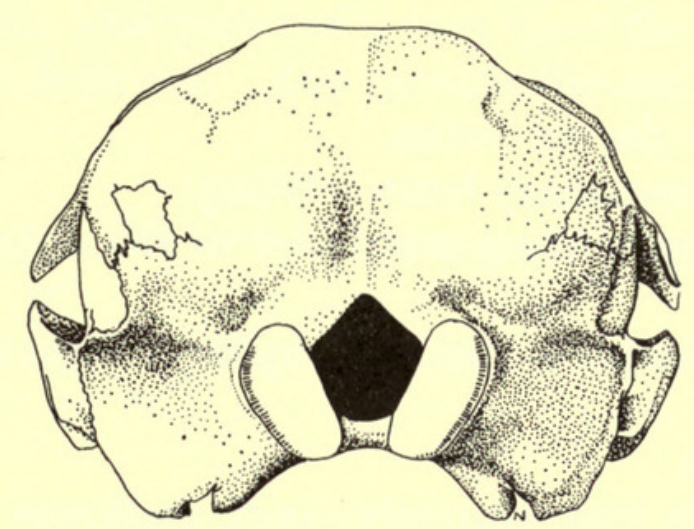

(C)

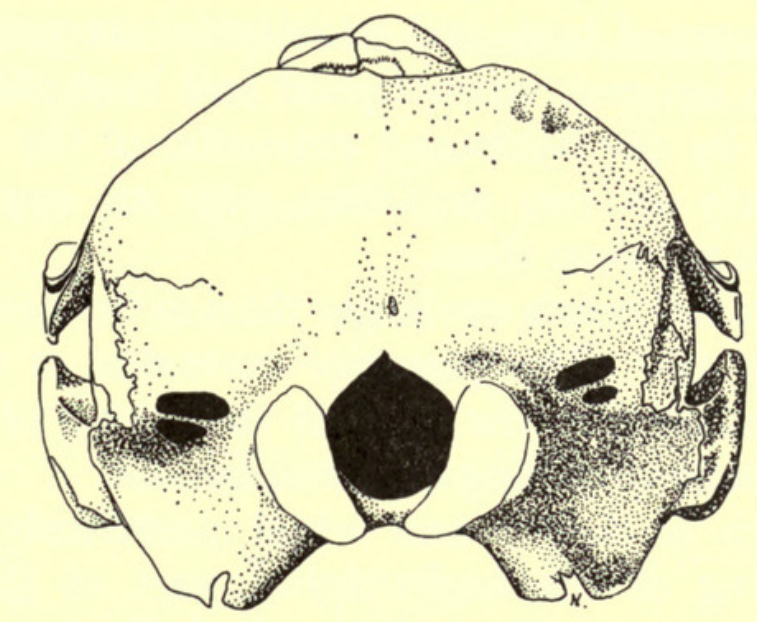

(D)
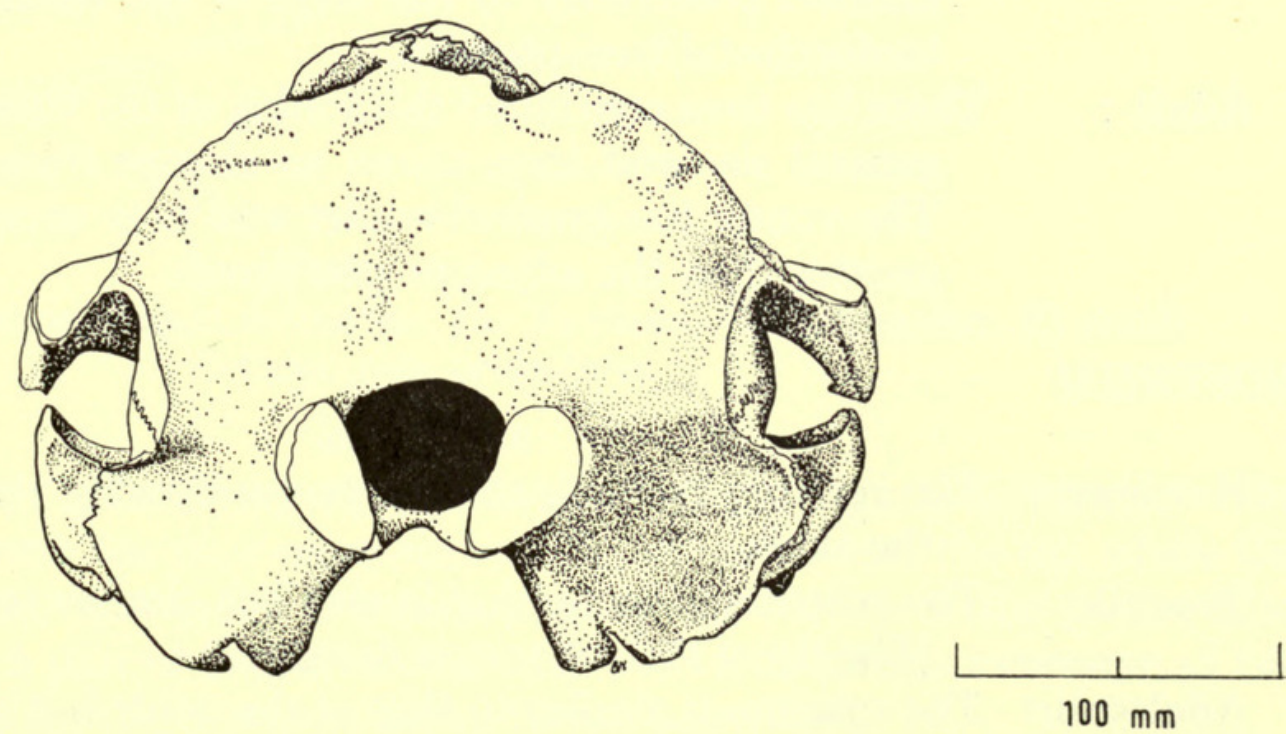

FIg. Io. Caudal view of skulls of P. electra ; (A) Newborn, (B) Juvenile, (C) Adolescent, (D) Adult. Orthographic projections. 
squamous portion of the squamosal still occupies a relatively small portion of the temporal area.

Adolescent : The post-temporal fossa is clearly defined as in the adult. The squamous portion of the squamosal has increased its area to occupy the lower third of the temporal area.

Adult : $\quad$ There is very little change, except that the ridges demarcating the fossa have become better defined, and the caudal angle has a well defined pyramidal eminence.

\section{Cranial Hiatus}

Newborn : Obscured by the ear bones.

Juvenile: There is no secondary bony infilling.

Adolescent : There is bony infilling restricted to the anterior half of the cranial hiatus.

Adult : $\quad$ The cranial hiatus is almost completely filled in by secondary bone.

\section{Basicranial Trough \& Crests}

Newborn : The trough is comparatively much shallower than in the adult skull. The sutures of basi- and exoccipital are present posteriorly. The junction between basioccipital and basisphenoid has not yet been covered by the backward extension of the vomer, which extends posteriorly as two processes with an appreciable area of basisphenoid between them.

Juvenile : The basicranial crests are larger than in the newborn, but they are not adult in size. The posterior extension of the vomer is damaged and is missing to the level of the suture of the basisphenoid with presphenoid, exposing the presphenoid.

Adolescent: The trough is deeper and wider posteriorly, and there has been thickening of the basioccipital part of the crests. The vomer extends posteriorly to the level of the suture between pterygoid/ basioccipital/basisphenoid.

Adult : $\quad$ There has been continued thickening of the basicranial crests, but the general size and form shows no change from the adolescent skull. The vomer has grown broader and now occupies a width which is greater than the adjacent pterygoids.

\section{ROSTRUM}

\section{a. General}

Newborn : The rostrum is much smaller proportionally than the cranial part of the skull.

Juvenile : The rostrum is increasing in size but similar to that of the newborn. (The tip of the rostrum is damaged).

Adolescent : The rostrum is similar to that of the adult but rather more slender. Adult : $\quad$ The rostrum is robust and in lateral view is wedge shaped proximally, flattening out distally. 


\section{b. Cross Section}

Newborn : The base of the rostrum is dished, the lateral border of the maxillae is turned up proximally to form a low crest. Anterior to the apex of the prenarial triangle the dorsal surface of the premaxillae is at an angle to the maxillae, the angulation increasing distally to the premaxillary crests.

Juvenile : The base of the rostrum is dished with the lateral crests more pronounced. The premaxillae have lost their angularity with the maxillae, and posteriorly they have the contour of the adult.

Adolescent : The base is flatter. The premaxillae are as in the adult.

(A)

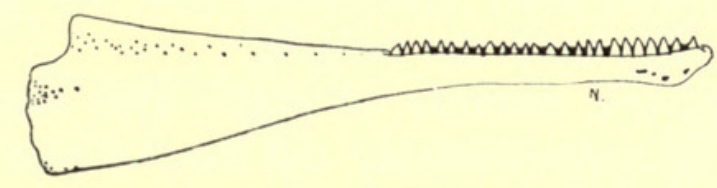

(B)

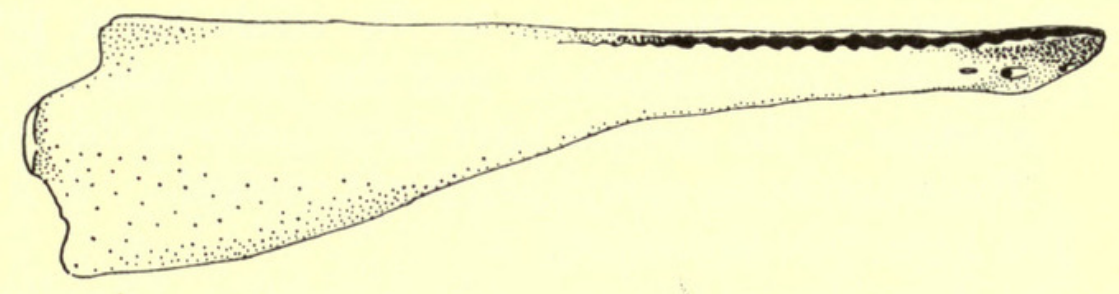

(C)

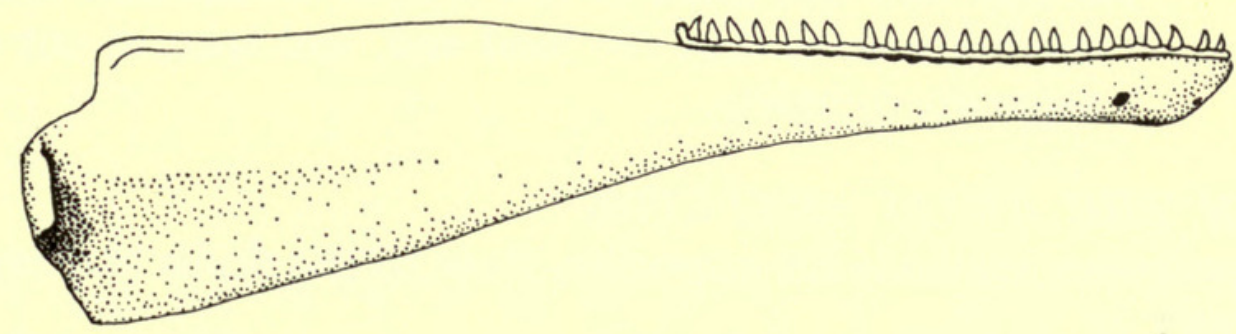

$100 \mathrm{~mm}$

FIG. I I. Lateral view of right mandible ; (A) Newborn, (B) Adolescent, (C) Adult.

Orthographic projections.

Adult : $\quad$ The base is flattened with the lateral margin slightly upturned. The rostrum becomes more convex distally until near the tip, where the regular convexity is interrupted by the flexing of the premaxillae into a pair of crests, which, with the cartilaginous extension of the nasal septum between them, form a blunt keel.

$$
\text { c. Rostral extension of the Nasal Septum }
$$

This has been discussed in the cranial region. 


\section{Tooth Rores and Alveoli}

Newborn : The alveolar grooves form continuous furrows with only the slightest indication of the septa of the alveoli. The teeth are closely set together, and their crowns are exposed to a small extent. The grooves are lateroventrally orientated.

Juvenile : The alveolar grooves are still continuous furrows, but the individual alveoli are just perceptible by the slightest development of the septa. The grooves are ventrally orientated, but laterally exposed towards the tip. The teeth are missing.

Adolescent : The alveolar grooves, although continuous furrows, are interrupted lingually and labially by ill-defined alveolar septa. The grooves are more ventrally orientated and the alveoli are more widely spaced. The teeth are missing.

Adult : The sockets are discrete alveoli. The teeth are separated by a distance of approximately the basal diameter of the teeth. Some teeth are present, and their crowns are not well worn.

\section{LOWER JAW}

Newborn: The general outline is as in the adult lower jaw. The alveolar grooves are continuous, and the teeth are in contact with one another. The crowns have grown above the top of the grooves. The mandibular symphysis is not ossified.

Juvenile : The lower jaw is missing.

Adolescent : The same general features as in the adult. The alveoli are defined by the still incompletely ossified septa.

Adult : The two rami are fused at the ossified mandibular symphysis. The teeth are vertical at the hind end, and splayed out distally. The septa are complete.

\section{NOTES ON THE AXIAL SKELETON}

Of the specimens available for inspection three of the skulls had associated vertebral columns :

$$
\begin{array}{ll}
\text { Newborn : } & \text { I965.6.2.I } \\
\text { Adolescent : } & \text { I959.7.9.2. } \\
\text { Adult : } & \text { W.A.M. } 4798
\end{array}
$$

There was no axial skeleton to represent the juvenile phase in the comparison. None of the vertebral columns is complete but the portions that were available give information about the development of the axial skeleton; it was not possible to define the vertebral formula, but Nakajima and Nishiwaki (I965) give it as $C_{7}$ (3 fused) $+\mathrm{Dr}_{4}+\mathrm{LI} 7+\mathrm{Ca} 44=82$.

\section{Axial Skeleton of P. electra}

Newborn : The cervical vertebrae of the newborn are all separate. The paired components forming the neural arches of the cervical and the first ten thoracic vertebrae are neither fused with their centra nor with 
each other apically. The paired components of the atlas, axis and third cervical vertebra are not fused together (fig. I2). The inferior arch of the atlas is not fused to the centrum of the axis and the latter is still separate from the third vertebra.

The epiphyses of all vertebrae are unfused.

From D.II the neural arches, while still not joined to their centra are joined apically. Caudally the neural arches are certainly present to the 54th vertebra. All are fused apically and none is fused to its

(A)

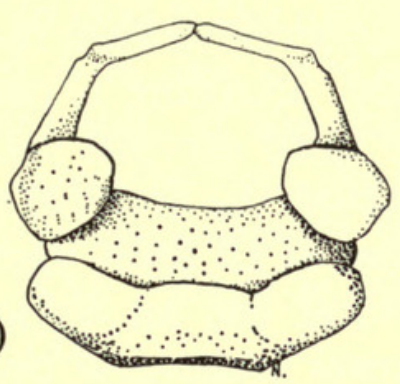

(B)

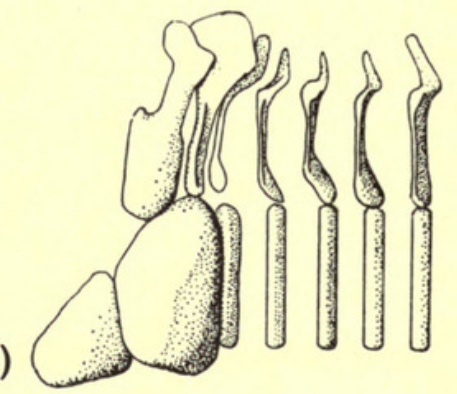

(C)

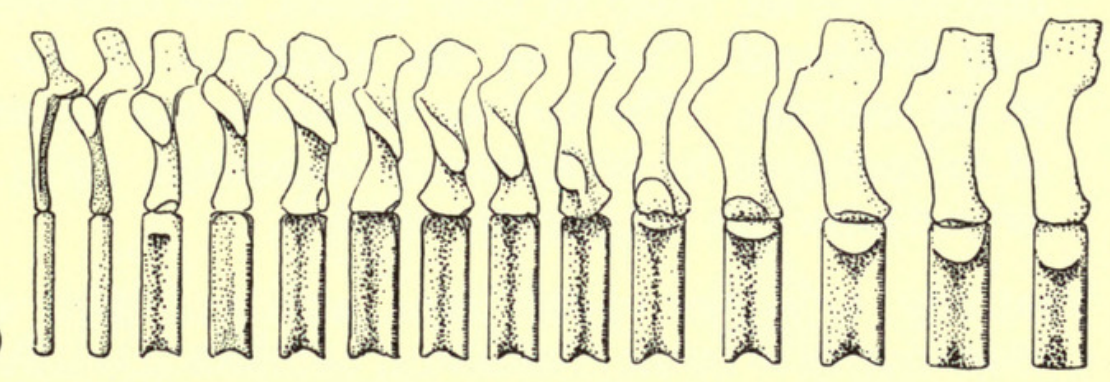

(D)

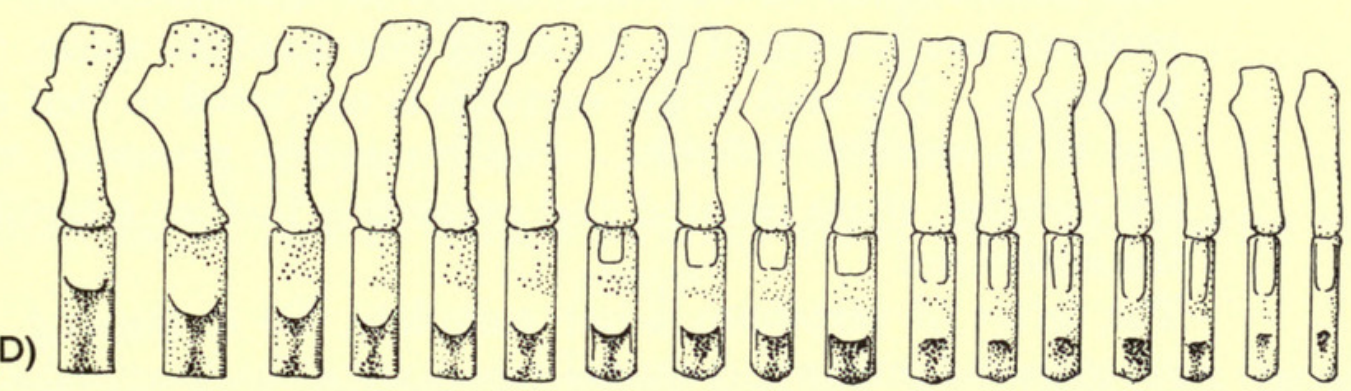

(E)

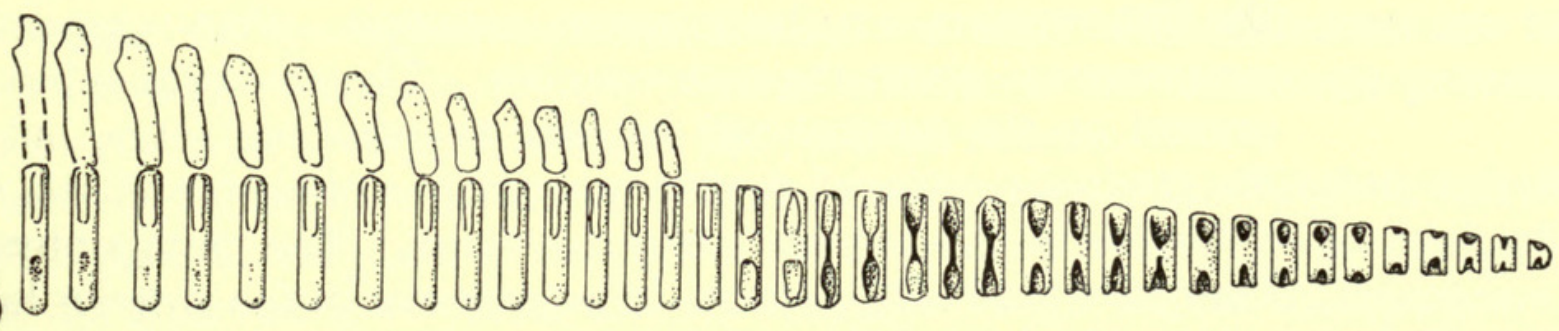

FIG. I2. Semi-diagrammatic drawing of reconstruction of incomplete vertebral column of newborn. 
centrum. Incipient transverse processes stem from the neural arches of the first I 7 vertebrae, from which point caudally they can be distinguished on the centra, diminishing to disappearance in the posterior caudal region. Rudimentary superior transverse processes are present on the vertebral arches of the 4 th -7 th cervical vertebrae, but there are no indications of inferior transverse processes.

Adolescent : The atlas, axis and third cervical vertebra of the adolescent are fused ; the atlas and axis being joined at the neural spine and base of the centrum. There is still separation between the neural arches of the atlas and axis dorsolaterally, affording a passage for the second cervical spinal nerve. The third cervical vertebra is fused to the posterior face of the axis, though the limits of the two centra can be discerned. The neural spines of all three vertebrae are fused with each other. The third cervical has an obvious upper transverse process and rudimentary lower transverse process.

The vertebrae are at an advanced state of development ; the vertebral arches are fused to their centra, the transverse processes are well developed. None of the epiphyses of the centra is fused to its centrum. The last Io vertebrae are missing (from a total of 82 indicated by Nakajima \& Nishiwaki, I965). Neural arches extend tailwards to the $59^{\text {th }}$ vertebra.

Adult : Ventrally, ankylosis of the atlas, axis and third vertebra is more extensive than in the adolescent, but dorsolaterally the limits of the centra of the third cervical vertebra and the axis are still traceable. The neural spine of the axis, which in the adolescent is bluntly pointed, has developed in the adult into a robust spine, terminally bifurcate. The arch of the vertebra is not fused to that of the axis and is incomplete apically. The transverse processes of the axis are rounder, more pointed and extending further laterally than in the adolescent.

The series of vertebrae is not complete, C6 is missing and there are gaps in lumbar and caudal successions, the terminal caudals are all absent. Nevertheless the vertebrae remaining indicate by the absence of unfused epiphyses that the animal was physically mature. The apex of the anticline of the neural spines is at about the 3 oth vertebra in both adolescent and adult. Post-zygapophyses are present to about the $I_{5}$ th vertebra. The pre-zygapophyses are present on the cervical and anterior thoracic vertebrae, but they are gradually replaced by the increasing prominence of the metapophyses in the anterior thoracic region. The metapophyses in their turn gradually decrease in prominence in the anterior lumbar region, but behind the anticlinal apex they are strongly developed up to the point where the vertebral arches begin to disappear. 


\section{Rib Neck Vestiges}

The existence of rib neck vestiges on transverse processes has been noted by Flower (I872), Slijper (I936) and Fraser (I940). Slijper notes the condition in L. albirostris so far as the genus Lagenorhynchus is concerned. The presence of these rib neck vestiges is associated with a change in the attachment of the ribs to the vertebral column. In the adult and adolescent electra there are five and six ribs respectively which possess both capitulum and tubercle. The remaining ribs have neither neck nor capitulum. This change from complete to 'tubercular' ribs is clearly defined on the ribs themselves, but on the associated vertebrae it is expressed as a transitional series, so that if the number of complete ribs is five (as in the adult), the vertebra associated with the sixth rib has attached to it a capitular portion differing very little from that of the preceding rib, except that it is fused to the transverse process and separate from the rib (fig. I3). The heads of the vestiges are in very close proximity to the articular facets on the fifth vertebra, and themselves bear articular facets. The vestige is missing on this vertebra in the adolescent, which has six complete ribs.

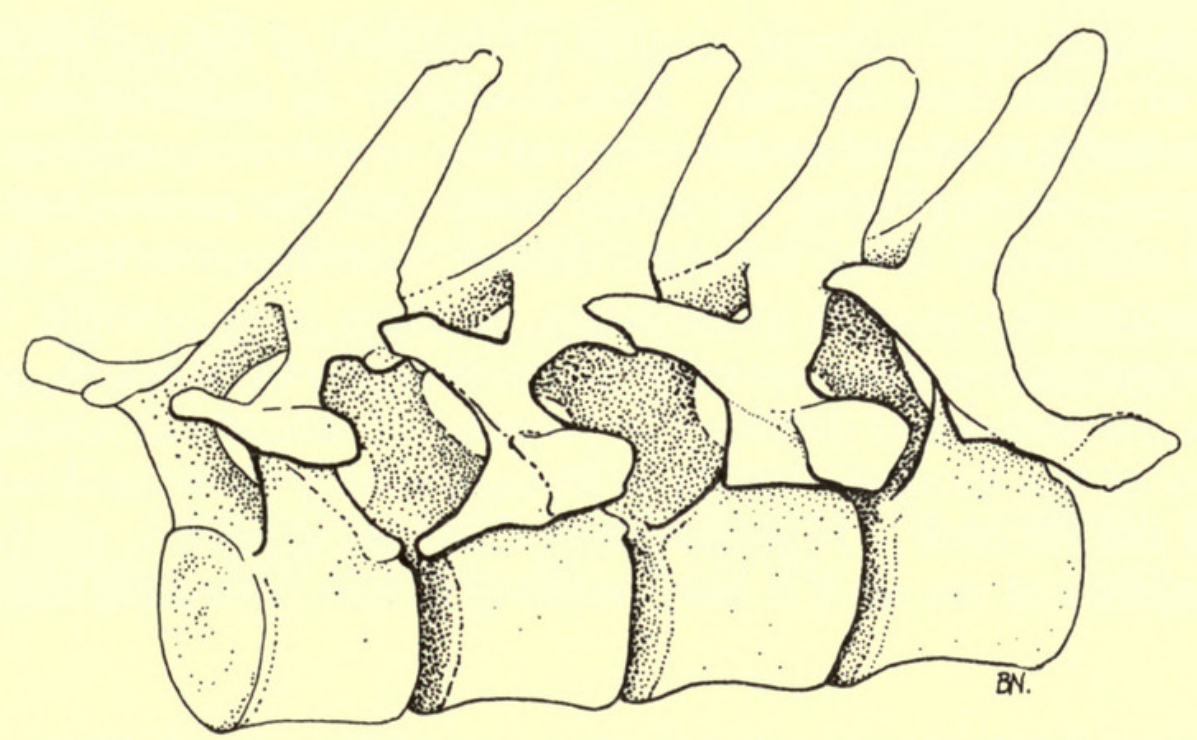

FIG. 13. Anterolateral view of thoracic vertebrae 5-8 of adult, to show the rib neck vestiges.

On the transverse processes of the seventh thoracic vertebra of both the adult and adolescent, there are bilateral, short, hook-like processes whose apices point in the direction the necks of the ribs would follow if present, toward vestigial catapophyses on the vertebra in front.

The vestiges on the eighth vertebra of both the adult and adolescent are low, barely perceptible eminences on the ventral surfaces of the transverse processes. There are very reduced catapophyses on the vertebra in front.

The articular facets for the tubercles of the ribs on the sixth and eighth, and fifth and eighth thoracic vertebrae in the adolescent and adult respectively, are oval, while those of the intervening vertebrae are sub-triangular, implying the incorporation of additional bony elements.

In terrestrial mammals, the majority of the ribs have distinct tubercle and 
capitulum. The cetaceans are distinguished by the increased number of ribs having single articulation with the corresponding vertebra. The odontocetes have three patterns of vertebra-rib connection ; anteriorly, a double connection at the head and tubercle with the centrum and transverse process respectively; further back, a tuberculo-transverse process articulation only; caudally, there are rib elements which do not have an obvious articulation with the vertebral column. It may be noted further that in odontocetes, the sternal ribs are completely ossified.

The form of double articulation of the ribs with the vertebral column, and possession of ossified sternal ribs anteriorly, indicate the rigidity of the fore part of the rib basket. Posteriorly, the thoracic cage, being without capitular-centrum connections of the ribs and having a much looser association with the sternum, would allow greater flexibility of the body, as pointed out by Slijper.

The connection of the head to trunk demands a strong framework for the relevant musculature, part arising from the vertebral column, part from the ribs, and part from both. Further, the attachment of the pectoral limbs is dependent on muscles arising from anterior vertebrae and ribs, again demanding stability of the rib cage for their proper functioning.

The locomotion of these animals requires a flexibility of the vertebral column and development of axial musculature. This flexibility is initiated in the posterior thoracic region and is achieved by reduction of the vertebral apophyses and development of the inter-vertebral discs ; it seems likely that the removal of the capitular articulation in this region in the vertebral column contributes to this flexibility.

The enlargement of the axial musculature required in connection with cetacean locomotion necessitates a complementary extension of neural spines and transverse processes. In the individual dolphin the progressive lateral extension of the transverse processes of the thoracic vertebrae is unavoidably associated with increasing attenuation of the rib neck. It seems reasonable that a point is reached where the mechanical stability of the neck is lost, resulting in ribs possessing tubercles only.

\section{Summary}

Two specimens of dolphin stranded on the coast of New South Wales are identified as belonging to the species Peponocephala electra. As Gray's description of the holotype of Lagenorhynchus electra is brief, a redescription is given, together with orthographic projections of various aspects of the skull. Ten skulls available for comparison have been measured and the data applied to quantitative assessment of the skull. A topographical survey was made of four skulls of increasing age to show the changes in skull form from birth to physical maturity. Comparative notes have been made of some of the alterations in the axial skeleton with age.

\section{ACKNOWLEDGMENTS}

The authors are indebted to Professor Kenneth Norris, University of California, for making available the skeleton of the newborn specimen, Dr. D. L. Ride, Director of the Western Australian Museum for lending the skeleton W.A.M. 4798, and to Dr. R. G. Van Gelder, American Museum of Natural History, New York, for the loan of the specimen A.M.N.H. 4300. 
Thanks are due to the many people who wrote or sent photographs relating to the Crowdy Heads school, especially Mrs. W. J. Ward, Mr. H. Anderson and Mr. L. Elford.

\section{REFERENCES}

Dawbin, W. H. I963. Mass stranding of dolphins Lagenorhynchus sp. Bull. Aust. mamm. Soc. $6: 14$.

Flower, W. H. I876. An introduction to the Osteology of the Mammalia. 2nd ed. Revised. I-344. London (Macmillan \& Co.)

Fraser, F. C. I940. Three anomalous dolphins from Blacksod Bay, Ireland. Proc. R.Ir.A. $45:$ B, I7 : 4I3-455.

\& Purves, P. E. 1960. Hearing in Cetaceans-II Evolution of the accessory air sacs and the structure and function of the outer and middle ear in Recent Cetaceans. Bull. Brit. Mus. (N.H.), 7 : No. I, I-I40.

\& NoBle, B. A. I968. Skull of Lagenorhynchus cruciger from Livingston Island, South Shetland Islands. Bull. Br. Antart. Surv. $15: 29-38$.

Goodwin, G. G. I945. Record of a porpoise new to the Atlantic. J. Mammal. 26 : I95.

GraY, J. E. I846. Zoology of the Voyage of H.M.S. Erebus and Terror . . . I839-43. 1 (Mammalia) : 13-53.

Howell, A. Brazier I930. Aquatic Mammals. I-338. Baltimore (Charles C. Thomas).

NaKajima, M. \& Nishiwaki, M. I965. The first occurrence of a porpoise (Electra electra) in Japan. Sci. Rep. Whales Res. Inst. 19 : 91-104.

Nishiwaki, M. \& Norris, K. I965. A new genus, Peponocephala, for the odontocete cetacean species Electra electra. Sci. Rep. Whales Res. Inst. Tokyo. 20 : 95-99.

Owen, R. I866. On some Indian cetacea collected by Walter Elliott, Esq. Trans. zool. Soc. Lond. $6:$ I 7-47.

Peale, T. R. I848. United States Exploring Expedition during the years $1838-1842$, under the command of Charles Wilkes U.S.N. 8 (Mammalogy \& Ornithology) : xxv+ I7-388. Philadelphia.

SliJPER, E. J. I962. Whales. I-475. London (Hutchinson).

True, F. W. I889. Contributions to the natural history of the cetaceans. A review of the family Delphinidae. Bull. U.S. natn. Mus. 36 : I-192.

William H. Dawbin, D.Sc.

School of Biological Sciences

UNIVERSITY OF SyDNEY

N.S.W., Australia

Bruce A. Noble, B.Sc.

c/o British Museum (Natural History)

CRomwell Road

LoNDON, S.W.7

Francis C. Fraser, C.B.E., D.Sc., F.R.S. c/o British Museum (Natural History)

CRomwell RoAd

LONDON, S.W.7

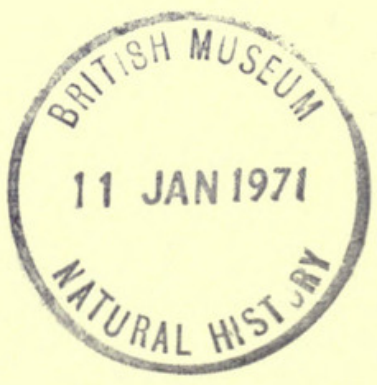




\section{$2 \mathrm{BHL}$ Biodiversity Heritage Library}

Dawbin, William H., Noble, B A, and Fraser, F. C. 1970. "Observations on the electra dolphin Peponocephala electra." Bulletin of the British Museum (Natural History) Zoology 20, 173-201. https://doi.org/10.5962/bhl.part.2255.

View This Item Online: https://www.biodiversitylibrary.org/item/19607

DOI: https://doi.org/10.5962/bhl.part.2255

Permalink: https://www.biodiversitylibrary.org/partpdf/2255

\section{Holding Institution}

Natural History Museum Library, London

\section{Sponsored by}

Natural History Museum Library, London

\section{Copyright \& Reuse}

Copyright Status: In copyright. Digitized with the permission of the rights holder.

Rights Holder: The Trustees of the Natural History Museum, London

License: http://creativecommons.org/licenses/by-nc-sa/4.0/

Rights: http://biodiversitylibrary.org/permissions

This document was created from content at the Biodiversity Heritage Library, the world's largest open access digital library for biodiversity literature and archives. Visit BHL at https://www.biodiversitylibrary.org. 